\title{
Constructal design of salt-gradient solar pond fields
}

\author{
Daniel González ${ }^{1,2,3}$, José Amigo ${ }^{1,2,3}$, Sylvie Lorente ${ }^{4}$, Adrian Bejan ${ }^{5}$ and \\ Francisco Suárez ${ }^{1,2,3, *, \dagger}$ \\ ${ }^{1}$ Department of Hydraulic and Environmental Engineering, Pontificia Universidad Católica de Chile, Avda. Vicuña Mackenna 4860, \\ Macul, Santiago, Chile \\ ${ }^{2}$ Centro de Desarrollo Urbano Sustentable (CEDEUS), CONICYT/FONDAP/15110020, Santiago, RM, Chile \\ ${ }^{3}$ Center for Solar Energy Technologies (CSET), Santiago, RM, Chile \\ ${ }^{4}$ Université de Toulouse, INSA, Toulouse, France \\ ${ }^{5}$ Department of Mechanical Engineering and Materials Science, Duke University, Durham, NC, USA
}

\section{SUMMARY}

Salt-gradient solar ponds (SGSPs) are water bodies that capture and accumulate large amounts of solar energy. The design of an SGSP field has never been analyzed in terms of studying the optimal number of solar ponds that must be built to maximize the useful energy that can be collected in the field, or the most convenient way to connect the ponds. In this paper, we use constructal design to find the optimal configuration of an SGSP field. A steady-state thermal model was constructed to estimate the energy collected by each SGSP, and then a complementary model was developed to determine the final temperature of a defined mass flow rate of a fluid that will be heated by heat exchangers connected to the solar ponds. By applying constructal design, four configurations for the SGSP field, with different surface area distribution, were evaluated: series, parallel, mixed series-parallel and tree-shaped configurations. For the study site of this investigation, it was found that the optimal SGSP field consists of 30 solar ponds of increasing surface area connected in series. This SGSP field increases the final temperature of the fluid to be heated in $22.9 \%$, compared to that obtained in a single SGSP. The results of this study show that is possible to use constructal theory to further optimize the heat transfer of an SGSP field. Experimental results of these configurations would be useful in future works to validate the methodology proposed in this study. Copyright (C) 2016 John Wiley \& Sons, Ltd.

\section{KEY WORDS}

solar energy; salt-gradient solar pond; constructal theory; renewable energy systems; sustainable development

\section{Correspondence}

*Francisco Suárez, Pontificia Universidad Católica de Chile. Avda. Vicuña Mackenna 4860, Departamento de Ingeniería Hidráulica y Ambiental, Macul, Santiago, Chile.

${ }^{\dagger}$ E-mail: fsuarez@ing.puc.cl

\section{INTRODUCTION}

To achieve sustainable development, the current world approach to energy is toward finding more alternatives for renewable energy sources. In addition to the wellknown methods to collect solar energy (e.g. photovoltaic cells, solar collectors and solar cells), salt-gradient solar ponds (SGSPs) appear as an alternative method for solar collection and storage of low-grade heat [1].

SGSPs are water bodies that capture and accumulate solar energy for long time periods [2-6]. These are artificially stratified by dissolving salts with different concentrations to form three characteristic zones (Figure 1): the upper convective zone (UCZ), the non-convective zone (NCZ) and the lower convective zone (LCZ), which is also known as the storage zone. The UCZ is a thin layer of water with low salinity and temperature. The NCZ is a layer formed by a salinity gradient where temperature increases with depth. Because the effect that the salinity gradient has over the density of the fluid is larger than that of temperature, the NCZ acts as a static barrier of fluid that suppresses global convection within the solar pond. This density gradient allows the NCZ to insulate the LCZ. The LCZ is a layer of fluid with high levels of temperature and salinity. The solar radiation that reaches the LCZ warms the hot brine and allows storing significant amounts of energy [1], which can be used in low-temperature applications, such as building heating [6,7], thermal desalination [8], industrial heat process $[9,10]$, among other applications [11-13]. 


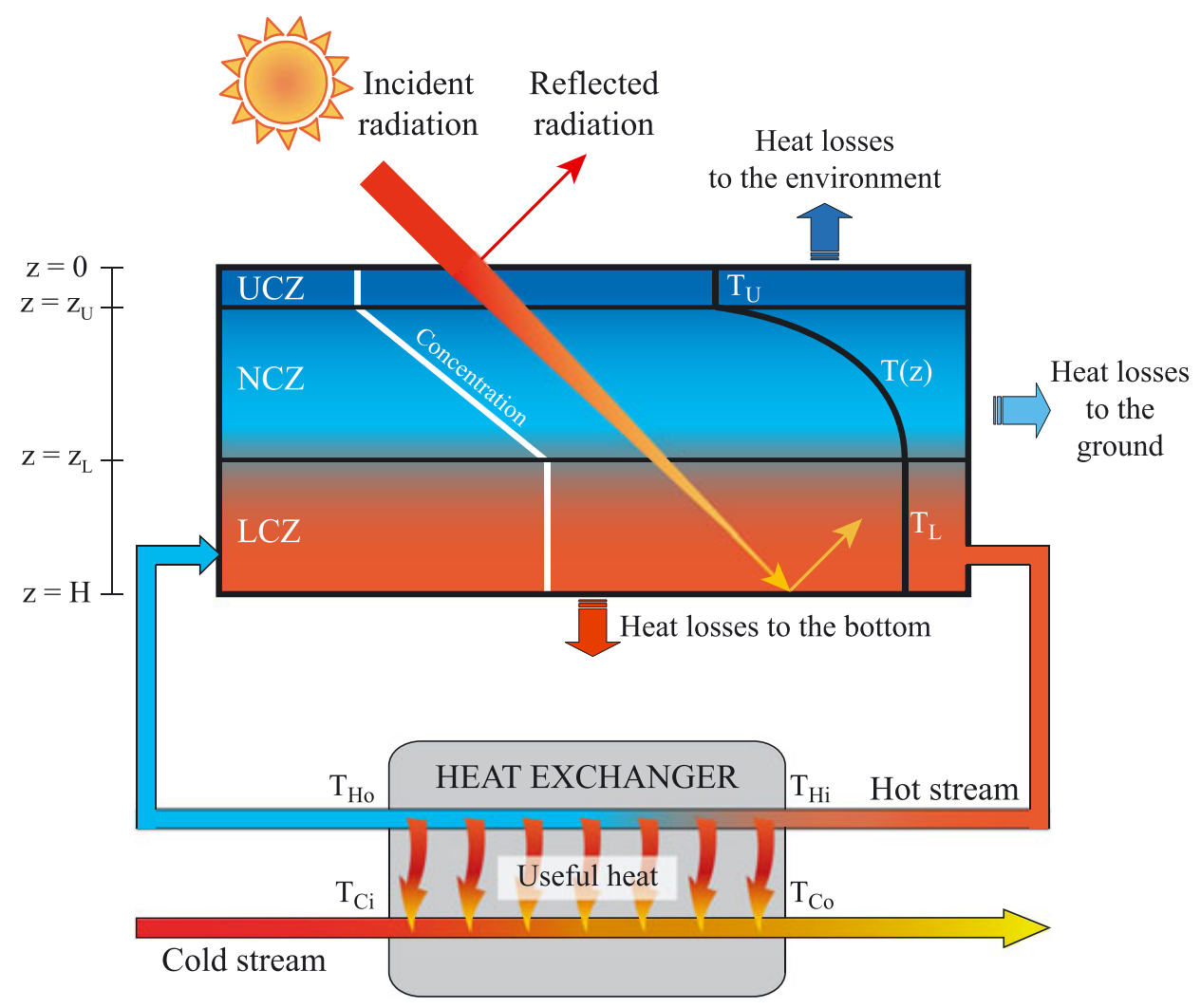

Figure 1 Configuration of the SGSP and the heat fluxes used to develop the mathematical model (see Appendix A for more details about the thermal model). The connection between the solar pond and its heat exchanger is also shown. Heat is transferred from the lower convective zone (hot stream) to the stream of water to be heated (cold stream).

Solar ponds have been built in many locations around the world [14], ranging from small experimental solar ponds $\left(\sim 1 \mathrm{~m}^{2}\right.$ of surface area) to large solar ponds ( 20 ha). For instance, the Beith Ha'Arava Solar Pond Power Plant had a surface area of $210000 \mathrm{~m}^{2}$ and sustained a $5 \mathrm{MW}_{\mathrm{e}}$ power plant [15]. To store maximum energy, it is common to have a single SGSP with a surface area that covers most of the available land. However, having a single SGSP can be inefficient when pond failure occurs. For instance, on May $18^{\text {th }}, 1991$ the Bhuj solar pond (India) experienced a $5-\mathrm{cm}$ drop of pond level when the temperature in the LCZ was higher than $95^{\circ} \mathrm{C}$ [11]. This drop occurred because of a leakage from the bottom of the pond. Although attempts were made to repair the leak without stopping the operation, it was impossible to fix the liner without emptying the pond. Therefore, the stored energy was lost, and no energy was stored or produced while the system was under repair. Some works have proposed to build more than one SGSP to allow energy collection and storage in case one pond is not working properly [10,11], or for another purposes [15]. However, the design of a solar pond field has never been analyzed in terms of number of solar ponds that must be built to maximize the useful energy, or the most convenient way to connect the ponds.

A promising way to improve the architecture of a finitesize flow system is the use of constructal design [16].
Constructal theory proclaims the existence of an equilibrium flow architecture; or nature flow architecture, where all the possibilities of incrementing the performance of the system have been exhausted. This theory indicates a pathway or a strategy to be followed that helps finding the best configuration of a system - in this case an SGSP field - to minimize the resistances of the system's flow currents. The flow currents could be fluid flow [17], heat flow [18-21], strain [22] or the flow of any other substance that flows within the system $[23,24]$.

Constructal theory has been applied in many domains, which are reviewed regularly [16,22,25]. For example, Wechsatol et al. [17] developed an optimal design of a network of pipes to uniformly distribute hot water around an area. Kim et al. [23] designed the optimal shape of the flow architecture in self-healing vascular materials. They systematically solved the best way to distribute the flows by reducing their global resistance, and then this finding was reinforced with an analytical optimization. Miguel [26] investigated the generation of solar energy-based systems architecture using constructal theory. He studied a shading system to control the incoming solar radiation during summer and winter, a bundle of pipes to warm a room, and a distillation system integrated in the roof. Lorente et al. [18] showed how to use the constructal theory to design the most efficient geometry of a solar chimney power 
production plant on an available land area. First, they found the relationship between maximum power and geometry, and demonstrated that the maximum power increases monotonically with the length scale of the plant. They presented several arrangements for distributing the multi-scale plants on a square area: few large and many small, in the right arrangement. The most important factor in their design is the land area allocated to the largest plant. They showed that the efficiency in power production also depends on the total land area that is being used. Lorente et al. [27] presented the fundamental tradeoffs that underpin the design of a distributed energy system with two objectives: the production and distribution of electric power driven by solar heating, and desalinated water produced by consuming solar power.

In this paper we consider the feasibility of designing an SGSP field using the principles of constructal law [16]. The objective is to find the best configuration of an SGSP field (shape and size of each solar pond, and distribution and number of ponds in the SGSP field) that can maximize the useful energy stored in the system. Although there are many factors that define the best configuration of an SGSP field (e.g. investment and operation costs), here we only focus on the heat transfer aspects. To achieve the objective of this study, a one-dimensional steady-state thermal model was developed to estimate the energy collected by each SGSP; next, the final (outlet) temperature of a mass flow rate to be heated in an SGSP field of fixed land area was calculated for different architectures of the SGSP field. The application of the constructal theory not only allowed understanding of the processes that maximize the outlet temperature, but also why some configurations perform better than others. As an illustration, the methodology to design an SGSP field was applied in the province of Copiapó, Chile, to pursue sustainable urban development in the city. The approach presented in this paper is general and is applicable to any design conditions.

\section{METHODS}

First, a mathematical model was developed to estimate the thermal behavior of an SGSP. This model is used to determine the SGSP thermal profile, to optimize the size of the SGSP and to estimate the temperature of the heat exchanger that is used to extract the energy from the pond. Second, a complementary model was developed to determine the final temperature of a specified mass flow rate of a fluid (water) that will be heated by the heat exchangers connected to the SGSP field.

\subsection{Thermal behavior of a single SGSP}

\subsubsection{SGSP model}

Several computational models have been developed to optimize the performance of an SGSP. There are many one-dimensional studies in steady or transient conditions $[8,28,29]$, and more sophisticated two-dimensional models that analyze in detail the hydrodynamics inside the pond [30-32]. In general, the one-dimensional steady models provide a good first approximation to determine the thermal performance of a solar pond, especially for analyzing changes in performance against parameter variations [6,33-36].

In the present study, we developed a simplified onedimensional thermal model for an SGSP under steady state conditions. The model estimates the thermal profile within the SGSP using the following assumptions: (i) the UCZ and LCZ are completely mixed, i.e. they have a uniform temperature; (ii) the UCZ-NCZ and NCZ-LCZ interfaces are at a fixed depth $z_{U}$ and $z_{L}$, respectively, as shown in Figure 1; (iii) the SGSP has a stable configuration; (iv) the thermal properties of the fluid are constant; (v) the temperature of the ground that surrounds the pond is constant and uniform; and (vi) all the radiation that reaches the LCZ is absorbed by the fluid in this zone. Appendix A provides a detailed description of the mathematical model. Here we outline the principles used to develop the model.

The model is based on the energy conservation principle within the different zones of the SGSP. In the UCZ, the energy balance considers shortwave radiation, heat losses through the water surface, heat losses through the sidewalls and conductive heat flux coming from the NCZ. In the LCZ, the energy balance takes into account shortwave radiation, heat losses through the bottom of the pond, heat losses through the side boundaries, useful energy, i.e. the energy extracted from the pond, and conductive heat flux transmitted to the NCZ. The energy balance in both the UCZ and LCZ considers that the temperatures of the $\mathrm{UCZ}\left(T_{U}\right)$ and the $\mathrm{LCZ}\left(T_{L}\right)$ are unknowns. These temperatures are related by the energy balance in the NCZ. Because the temperature in the NCZ is not uniform, the analysis of this zone is different than that performed in both the UCZ and the LCZ. Because of the density gradient, the fluid in the NCZ is static and thus the main heat transfer mechanisms in this zone are conduction and solar radiation absorption, in addition to heat losses to the sides. The equation that determines the temperature profile in the NCZ is:

$$
\frac{\partial^{2} T(z)}{\partial z^{2}}-\frac{T(z)-T_{g}}{\xi^{2}}=-\frac{\Phi_{h}(z)}{k}
$$

where $T(z)$ is the temperature at a depth $z, T_{g}$ is the ground temperature, $\xi$ is a characteristic length of the problem, $k$ is the thermal conductivity of the fluid and $\Phi_{h}(z)$ is the shortwave radiation, which is modeled as a volumetric heat source. The shortwave radiation is assumed to be distributed within the water column as this radiation flux penetrates the fluid surface and is attenuated through the water $[6,30,37]$.

The solution of equation (1) emerge as a linear combination of a homogeneous solution and a particular solution [38], where the temperatures of the UCZ and LCZ are used as boundary conditions, i.e. $T\left(z_{U}\right)=T_{U}$ and $T\left(z_{L}\right)=T_{L}$. By 
coupling equation (1) with the energy balances in the UCZ and LCZ, the temperatures $T_{U}$ and $T_{L}$ are found, and then the solution to equation (1) provides the thermal distribution within the NCZ. Therefore, for certain design parameters and meteorological conditions, the model yields the temperature profile and the useful energy of a solar pond under steady state conditions.

\subsubsection{Optimal shape and size}

The shape of an SGSP has an impact on the temperature that can be reached in the LCZ. Dehghan et al. [39] demonstrated that, for a specified surface area, circular solar ponds have superior thermal performance than square ponds. This superiority is principally attributed to the smaller sidewall heat losses associated with the smaller perimeter per unit area of the circular pond. In practice, small ponds $\left(<500 \mathrm{~m}^{2}\right)$ tend to be circular, while large ponds tend to be rectangular because the heat losses through their sidewalls are less important than those occurring in small ponds [14]. However, in this investigation heat losses are an important factor because several solar ponds will be connected for the same fixed land area. Therefore, circular ponds are used in all configuration contemplated for the SGSP field.

Another important aspect of the operation of an SGSP is to maximize the temperature in the LCZ, i.e. to optimize the thicknesses of each zone. In this work, the UCZ thickness is kept as small as possible to minimize heat losses to the environment [8]. We used an UCZ thickness of $0.3 \mathrm{~m}$ $[8,40]$. In the LCZ the theoretical highest temperature is reached when the LCZ thickness approaches zero. However, this is not practical, because it must be designed to allow energy storage during operation. Furthermore, a minimum depth of this zone is required to prevent erosion of the NCZ when withdrawing heat [15]. For all these reasons, we used a fixed LCZ thickness of $1.1 \mathrm{~m}$ as suggested by Garrido and Vergara [10]. Note that the model assumes that all radiation that reaches NCZ-LCZ interface is absorbed in the LCZ fluid. Therefore, the thickness of this layer is used only for estimating the lateral heat losses to the ground.

As the thicknesses of the UCZ and the LCZ are fixed, the thickness of the NCZ (i.e. the depth of the interface NCZLCZ) is optimized for each pond to maximize the temperature in the LCZ. This is achieved in two ways: (i) given a fixed volume of SGSP, an optimal surface area can be found; or (ii) given a fixed surface area of the pond, an optimal depth can be found. Because in this study the constraint of the SGSP field is the fixed land surface, the optimal depth of the pond is found by fixing the SGSP surface area and maximizing the heat that can be extracted from the storage zone. This optimization is performed using the model detailed in Appendix A, by calculating the temperature of the LCZ for different depths of the pond.

\subsubsection{Heat extraction from the pond}

For practical reasons, an external heat exchanger (Figure 1) is used to extract the energy from the pond. This type of heat exchanger is selected because it requires less maintenance than a heat exchanger installed in the highly corrosive environment of the LCZ [41]. In this heat exchanger, the hot stream is the brine that is recirculated through the LCZ, and the cold stream is the fluid (water) that is to be heated. To describe the temperatures in the heat exchanger, the concept of effectiveness, $\varepsilon$, is used. Hence, the outlet cold stream temperature of the heat exchanger, $T_{C o}$, is defined by:

$$
T_{C o}=T_{C i}+\varepsilon \frac{C_{\min }}{C_{C}}\left(T_{H i}-T_{C i}\right)
$$

where $C_{\min }$ is the minimum between $C_{H}$ and $C_{C}$, and these are the capacity rates of the hot and cold streams, respectively; $T_{H i}$ is the inlet temperature of hot stream (which is equal to the LCZ temperature of the SGSP) and $T_{C i}$ is the inlet temperature of the cold stream, as shown in Figure 1.

The operation of the heat exchanger is also optimized to maximize the heat that can be transferred from the hot stream to the cold stream (cf. Appendix B). Indeed, as the hot-side mass flow rate increases, the heat transferred toward the cold stream increases. However, there is an upper bound to the increase in the hot-side mass flow rate, which is achieved when $C_{H}=C_{C}$. Therefore, the hotstream mass flow rate is determined using this condition.

\subsection{Configurations of the pond field}

A complementary mathematical model was developed to determine the final temperature of the stream to be heated by the heat exchangers connected to the solar ponds of the SGSP field. This section outlines the configurations that were used to connect the solar ponds, with the objective of finding the final temperature of the flow rate at the exit of the SGSP field.

There are two simple ways to connect the ponds when the total surface area is fixed: in series or in parallel. In addition, the SGSP field can be formed by connecting ponds in more complex configurations: ponds combined in series and in parallel (termed 'mixed series-parallel configuration'), and tree-shaped configurations. These configurations will be evaluated using the constructal theory, and adopting the following assumptions: (i) each SGSP has its own heat exchanger; (ii) the pipes that connect the ponds are well insulated, thus, the heat losses in the pipes are negligible compared to the other heat fluxes; and (iii) there is excess of freshwater to replenish the evaporation losses on the SGSPs, and excess of salts to maintain the salinity gradient in each solar pond.

In order to determine the cold stream outlet temperature in each heat exchanger connected to an SGSP, the temperature in the LCZ of the pond must be determined first. This is achieved using the thermal model described above for a circular SGSP with an optimal depth. Then, each heat exchanger is analyzed to find the temperature $T_{C o}$ that will be achieved by the stream of the cold side. The next subsections describe how the final temperature $\left(T_{F}\right)$ of the 
SGSP field is calculated for each one of the configurations described above. It is worth mentioning that the total land area $\left(A_{t}\right)$ is fixed, and it is the same for all configurations, with no restriction on the shape of the land area.

\subsubsection{Configuration in series}

In this configuration, the total area of the SGSP field $\left(A_{t}\right)$ is distributed in ponds connected one after the other (Figure 2). The cold stream outlet temperature of one heat exchanger is used as the cold stream inlet temperature of the next heat exchanger, and the final temperature of the water to be heated in the SGSP field is equal to the outlet temperature of the last SGSP/heat exchanger system.

Even when the total area of the SGSP field is fixed, there are many ways to distribute this area among the ponds connected in series. In this work, three combinations are evaluated: uniform, increasing and decreasing area distribution (Figure 2). The area of the $i^{\text {th }}$ SGSP, $A_{i}$, is calculated as follows:

$$
\begin{gathered}
A_{i}^{\text {uniform }}=\frac{A_{t}}{N} \\
A_{i}^{\text {increasing }}=\frac{2 i}{N(N+1)} A_{t} \\
A_{i}^{\text {decreasing }}=\frac{2(N+1-i)}{N(N+1)} A_{t}
\end{gathered}
$$

where $N$ is the total number of ponds. In the configuration in series, the cold stream mass flow rate of all the heat exchangers will be the same.

\subsubsection{Configuration in parallel}

In this configuration, the total area is distributed in ponds that are located side by side (Figure 3). Therefore, the cold stream inlet temperature of each heat exchanger $\left(T_{C i}\right)$ is the same as the temperature at the entrance of the SGSP field $\left(T_{o}\right)$. The total area of the SGSP field can be distributed using solar ponds with uniform or variable areas (Figure 3). For the case of uniform area, $A_{i}^{\text {uniform }}$ is calculated using equation (3). For the case of variable area, $A_{i}^{\text {variable }}$ is estimated using equation (4).

When the solar ponds are connected in parallel, the total mass flow rate entering the SGSP field $\left(\dot{m}_{t}\right)$ can be distributed equally to the ponds (equal flow) or in proportion with the surface area of each pond (proportional flow). For both uniform and variable surface areas with equal distribution of the mass flow rate toward the ponds, the cold stream mass flow rate of each heat exchanger is:

$$
\dot{m}_{i}=\frac{1}{N} \dot{m}_{t}
$$

For variable surface areas with proportional distribution of the mass flow rate, the cold stream mass flow rate of each heat exchanger is:

$$
\dot{m}_{i}=\frac{A_{i}}{A_{t}} \dot{m}_{t}
$$

The final temperature of the water to be heated in the SGSP field, $T_{F}$, will be a weighted average of the temperature reached at each SGSP/heat exchanger system:

$$
T_{F}=\frac{\sum_{i=1}^{N}\left(\dot{m}_{i} T_{C o_{i}}\right)}{\dot{m}_{t}}
$$

where $T_{C o_{i}}$ is the cold stream outlet temperature of the $i^{\text {th }}$ heat exchanger.

\subsubsection{Mixed series-parallel configuration}

In this configuration the distribution of the total area is generated using a combination of ponds connected in parallel and in series, as shown in Figure 4. First, the final temperature of the ponds connected in series is calculated. Then, this temperature is used to obtain the final temperature for the ponds connected in parallel. For simplicity, only mixed series-parallel configurations formed by the same number of ponds in series as in parallel are evaluated ('square' configuration). Therefore, the number of ponds is:

(a)

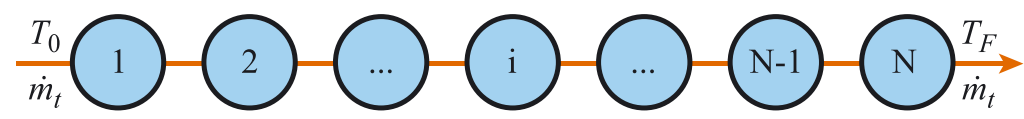

(b)

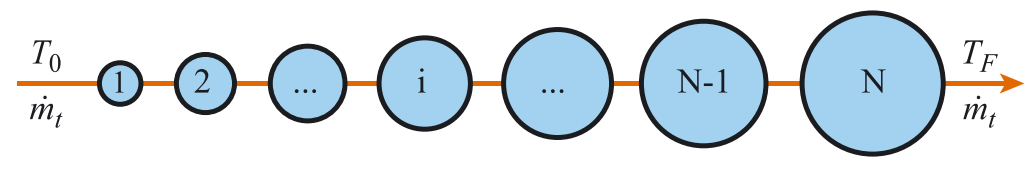

(c)

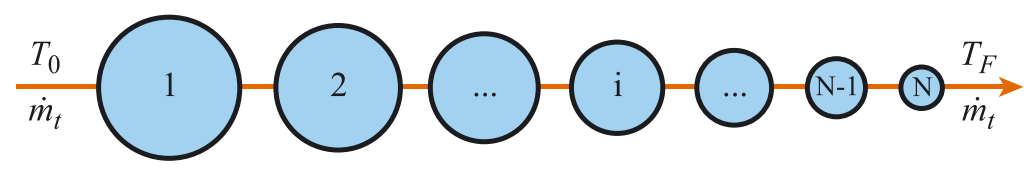

Figure 2 SGSP field made of $N$ solar ponds/heat exchanger systems connected in series. Distribution of the SGSP field total area for: (a) uniform area; (b) increasing area; and (c) decreasing area. 
(a)

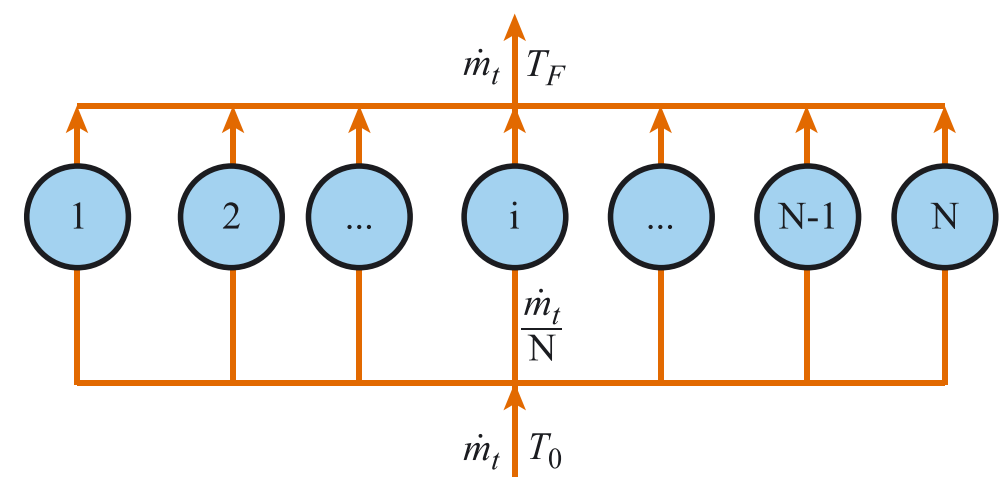

(b)

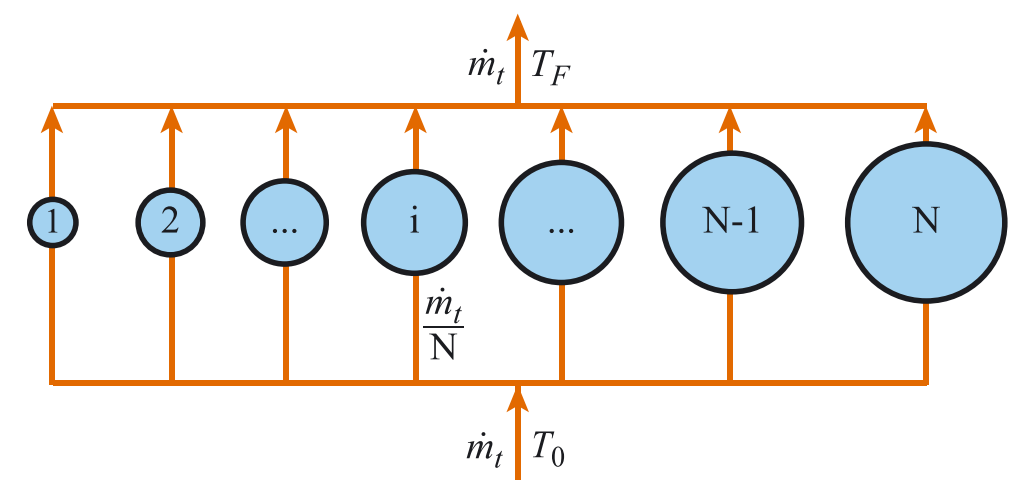

(c)

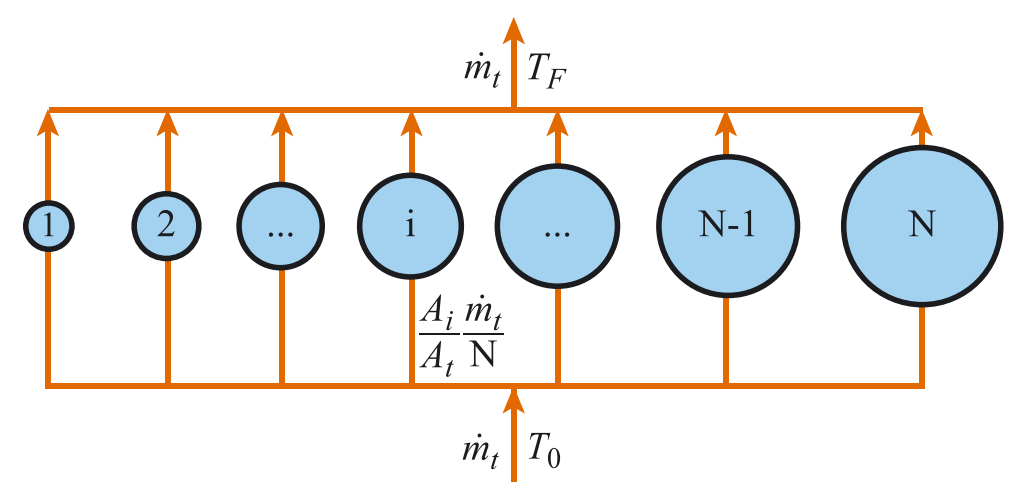

Figure 3 SGSP field made of N solar ponds/heat exchanger systems connected in parallel. Distribution of the SGSP field total area for: (a) uniform area; (b) variable area and equal flow (c) variable area and proportional flow.

$$
N=N_{s} N_{p}
$$

where $N_{s}$ is the number of solar ponds connected in series and $N_{p}$ is the number of solar ponds connected in parallel. The total area is distributed in a uniform way, as described in equation (3).

\subsubsection{Tree-shaped configuration}

A flow architecture derived from constructal law that is commonly used is the tree-shaped (dendritic) design. This architecture has been used in various technological applications [42-44]. Because of their multiple scales and optimized finite complexity, tree flows offer greater densities of heat and mass transfer [23]. Thus, we propose to study tree-shaped configurations where the solar ponds have decreasing, increasing or decreasing-increasing surface areas.

As shown in Figure 5, the tree-shaped configurations are characterized by having $n$ levels of solar ponds/heat exchanger systems. This type of configuration is a combination of ponds connected in series and in parallel - the flow is bifurcated into two in each of the branches in the decreasing area configuration (Figure 5a), and the flow converges from two branches in the increasing area configuration (Figure 5b). The 'mixed' decreasing-increasing area configuration (Figure 5c), which is similar than the trees matched canopy-to-canopy architecture [23], has solar ponds with variables areas, such that each surface area is proportional to the flow flowing in each heat exchanger of the corresponding SGSP. 


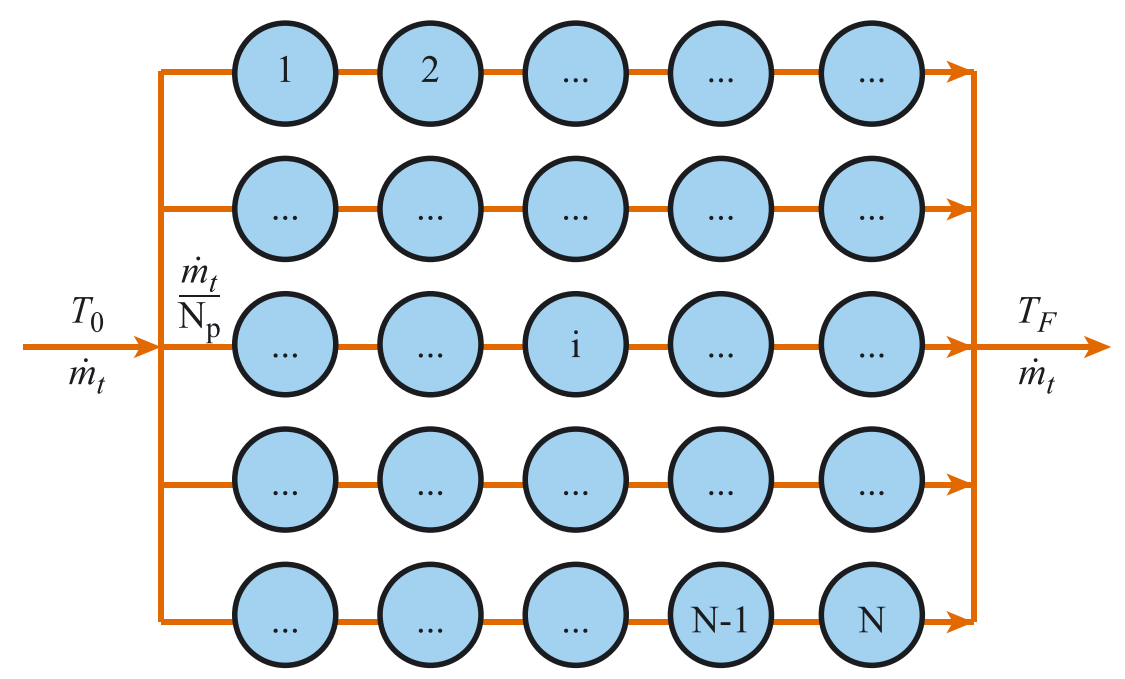

Figure 4 SGSP field made of N solar ponds/heat exchanger systems connected in a mixed series-parallel configuration (uniform area distribution).

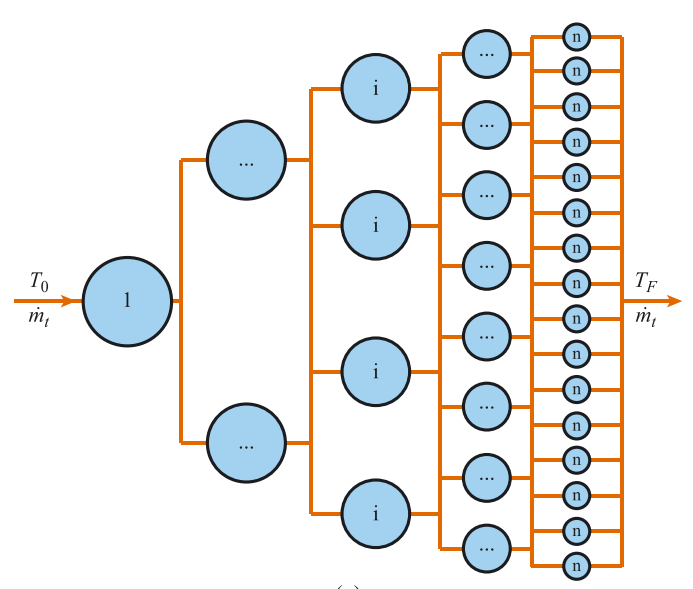

(a)
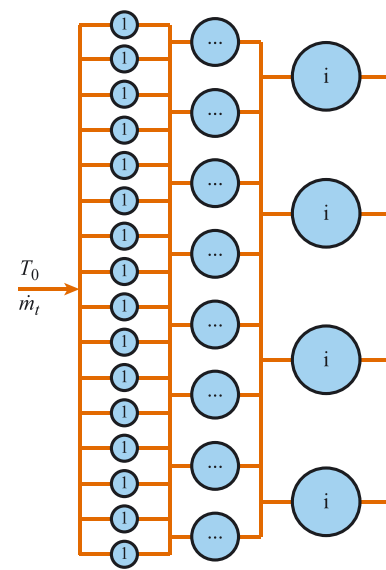

(b)

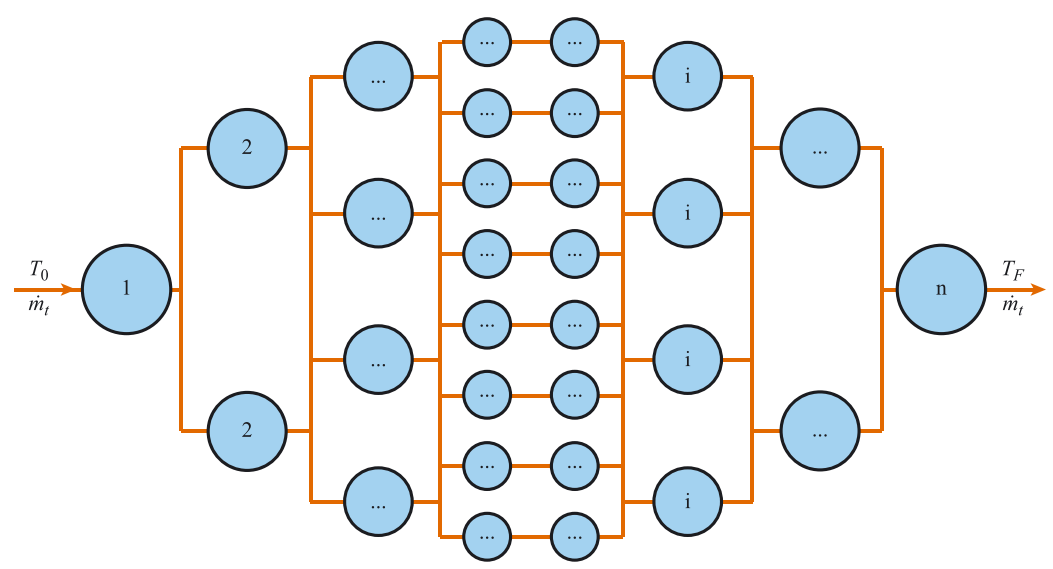

(c)

Figure 5 SGSP field organized in $n$ levels of solar ponds/heat exchanger systems connected in tree-shaped forms: (a) ponds with decreasing area; (b) ponds with increasing area and (c) ponds with a mixed decreasing-increasing area. 
To calculate the final temperature that is reached in such settings, only a single pond of each level (or branch) is modeled, because the other ponds of that level will be identical. Then, the total number of solar ponds for decreasing and increasing area configurations is calculated as:

$$
N=\sum_{i=1}^{n} 2^{i-1}
$$

where $n$ is the number of levels of each configuration. For the 'mixed' increasing-decreasing area configuration, the number of solar ponds is calculated as:

$$
N=\left\{\begin{array}{cc}
\sum_{i=1}^{n / 2} 2^{i} & \text { if } n \text { is even } \\
2^{(n-1) / 2}+\sum_{i=1}^{(n-1) / 2} 2^{i} & \text { if } n \text { is odd }
\end{array}\right.
$$

Because the total area of the SGSP field remains constant, the distribution of surface area for a solar pond in the $i^{\text {th }}$ level is as follows:

$$
\begin{gathered}
A_{i}^{\text {decreasing }}=\frac{A_{t}}{n 2^{i-1}} \\
A_{i}^{\text {increasing }}=\frac{A_{t}}{n 2^{n-i}} \\
A_{i}^{\text {mixed }}= \begin{cases}\frac{A_{t}}{n 2^{i-1}} & \text { if } i<\frac{n}{2}+1 \\
\frac{A_{t}}{n 2^{n-i}} & \text { if } i>\frac{n}{2}+1\end{cases}
\end{gathered}
$$

where the superscripts represent the type of configuration. The cold stream mass flow rate in each heat exchanger can be expressed as:

$$
\begin{gathered}
\dot{m}_{i}^{\text {decreasing }}=\frac{\dot{m}_{t}}{2^{i-1}} \\
\dot{m}_{i}^{\text {increasing }}=\frac{\dot{m}_{t}}{2^{n-i}} \\
\dot{m}_{i}^{\text {mixed }}=\left\{\begin{array}{ll}
\frac{\dot{m}_{t}}{2^{i-1}} & \text { if } i<\frac{n}{2}+1 \\
\frac{\dot{m}_{t}}{2^{n-i}} & \text { if } i>\frac{n}{2}+1
\end{array} .\right.
\end{gathered}
$$

For clarity, a summary of all the SGSP field configurations that were evaluated is shown in Table I.

\subsection{Parameters used to assess performance}

We evaluated the performance of the different configurations of an SGSP field placed near the city of Copiapó,

\begin{tabular}{|c|c|}
\hline Configuration & Area distribution \\
\hline \multirow{3}{*}{ Series } & Uniform \\
\hline & Increasing \\
\hline & Decreasing \\
\hline \multirow{3}{*}{ Parallel } & Uniform \\
\hline & Variable (with equal flow) \\
\hline & Variable (with proportional flow) \\
\hline \multirow[t]{2}{*}{ Mixed series-parallel } & Uniform \\
\hline & Decreasing \\
\hline \multirow[t]{2}{*}{ Tree } & Increasing \\
\hline & Mixed decreasing-increasing \\
\hline
\end{tabular}
Chile $\left(27^{\circ} 30^{\prime} \mathrm{S} 70^{\circ} 30^{\prime} \mathrm{W}\right)$. This city is located in a highly vulnerable basin that is currently in a state of acute water scarcity $[45,46]$. Therefore, we investigated the design of an SGSP field that could be used to provide energy for a thermal desalination system, such as that presented by
Table I. Summary of the SGSP field configurations that were evaluated in the present study.

Suárez et al. $[8,47]$. Describing that water treatment technology is out of the scope of this work. What is relevant for the current analysis is that the performance of the desalination system increases when the temperature of the feed water increases. Therefore, by maximizing the temperature of a fixed feed water flow rate, i.e. the mass flow rate to be heated in the SGSP field, the water treatment system will maximize its water production.

The operating parameters of the solar ponds used in this study were obtained from the performance optimization of each SGSP (as described above), and on the information available in the literature. We used a total land area of $23200 \mathrm{~m}^{2}$ (2.3 ha) for the SGSP field and a total mass flow rate of $6 \mathrm{~kg} / \mathrm{s}$. These parameters are the same than those used by Garrido and Vergara [10]. In terms of water production, and based on the information provided by the SISS [48], a mass flow rate of $6 \mathrm{~kg} / \mathrm{s}$ represents the water consumption of $\sim 3000$ inhabitants in the city of Copiapó ( $\sim 2 \%$ of the population of the city).

The meteorological parameters required to evaluate the performance of the SGSP field were obtained from Suárez et al. [46]. We used the mean annual values of the meteorological variables as the representative values for steady state conditions. The incident radiation was $212.5 \mathrm{~W} / \mathrm{m}^{2}$. The ambient temperature was $19.4{ }^{\circ} \mathrm{C}$, and we assumed that in steady state conditions the ground temperature is equal to the air temperature. The inlet temperature of the SGSP field was set to $15.3^{\circ} \mathrm{C}$ (data obtained from the Hydrographic and Oceanic Service of the Chilean Navy, http://www. shoa.cl). This temperature corresponds to the annual average temperature of the ocean near the town of Caldera, which is where water is currently being withdrawn, desalinated, and then used in the mining industry of the region, and for potable water use in the city of Copiapó [46].

For each pond, the thicknesses of the UCZ and LCZ were 0.3 and $1.1 \mathrm{~m}$, respectively [8,10]. The NCZ thickness of each pond within the solar pond field was optimized as explained before, and a minimum thickness of $0.5 \mathrm{~m}$ is used to avoid problems of salt gradient stability [14]. The thermal conductivity of the brine was $0.637 \mathrm{~W} / \mathrm{m} \mathrm{K}$ [14]. The heat transfer coefficient on the pond surface $\left(U_{S}\right)$ was estimated to the $92.24 \mathrm{~W} / \mathrm{m}^{2} \mathrm{~K}$. This value is based on the 
experimental data of Silva [49], and considers radiative, latent and sensible heat fluxes. The heat transfer coefficients of the sidewalls $\left(U_{U}, U_{N}\right.$ and $U_{L}$ for the UCZ, NCZ and $\mathrm{LCZ}$, respectively) correspond to those obtained when it is assumed that conduction is the main heat transfer mechanism. Considering a ground thermal conductivity of $2.4 \mathrm{~W} / \mathrm{m} \mathrm{K}$, and a distance of $4 \mathrm{~m}$ from the pond wall to the point where $T_{g}$ becomes constant [49], a value of $0.60 \mathrm{~W} / \mathrm{m}^{2} \mathrm{~K}$ is obtained for all the heat transfer coefficients of the sidewalls. The heat transfer coefficient of the bottom $\left(U_{B}\right)$ was set to $0.17 \mathrm{~W} / \mathrm{m}^{2} \mathrm{~K}$. This value was estimated assuming the same conditions than those used to estimate the sidewalls heat transfer coefficient, but considering a distance of $14 \mathrm{~m}$ from the pond's bottom to the point where $T_{g}$ becomes constant [50].

The heat exchanger effectiveness depends on the type of heat exchanger - the higher the effectiveness, the more energy that can be obtained from the ponds. For this study, the effectiveness was set to the reference value of $70 \%$. The specific heat of the hot stream (brine) was $3.570 \mathrm{~kJ} / \mathrm{kg}-\mathrm{K}$ [14], while the specific heat of the cold stream (water) was $4.181 \mathrm{~kJ} / \mathrm{kg}-\mathrm{K}$ [51].

\section{RESULTS}

\subsection{Thermal behavior of a single SGSP}

After defining the optimal shape of each solar pond (circular, as described above), it is necessary to determine the optimal thickness of the NCZ, i.e. the depth of the NCZ-LCZ interface, $z_{L}$ (Figure 1). Figure 6a shows the temperatures of the heat exchanger streams as a function of $z_{L}$, for a single solar pond occupying all the available land area. Recall that the inlet temperature of the hot stream is equal to the temperature of the LCZ, i.e. $T_{H i}=T_{L}$. For each $z_{L}$, the outlet temperature of the heat exchanger cold stream $\left(T_{C o}\right)$ is smaller than the inlet temperature of the hot stream $\left(T_{H i}\right)$ because the heat exchanger has a certain effectiveness. Even when the difference between $T_{H i}$ and $T_{C o}$ depends on the value of the effectiveness, the highest $T_{L}$ always agrees with the highest $T_{C o}$ and with the highest useful energy. The optimum $z_{L}$ was found to be $2.57 \mathrm{~m}$, from a total depth of $3.67 \mathrm{~m}$ and a brine volume of $85,237 \mathrm{~m}^{3}$. This depth produces the highest temperature in the LCZ (namely $68.5^{\circ} \mathrm{C}$, as shown in Figure 6b) and in the outlet of the heat exchanger cold stream $\left(52.5^{\circ} \mathrm{C}\right)$, delivering $933 \mathrm{~kW}$ of useful energy.

\subsection{Configurations of the SGSP field}

The following results are expressed in dimensionless form, where the final temperature $\left(T_{F}\right)$ and total brine volume $(V)$ of a particular configuration are normalized using the results obtained for a single SGSP, i.e. $\bar{T}=T_{F} / T_{\text {ref }}$ and $\bar{V}=V / V_{\text {ref }}$, where $T_{\text {ref }}=52.5^{\circ} \mathrm{C}$ and $V_{\text {ref }}=85,237 \mathrm{~m}^{3}$ are the reference temperature and brine volume, respectively. Furthermore, it is important to emphasize that the results of each of the following configurations use solar ponds operating under optimal conditions, i.e. the NCZ thickness of each SGSP is optimized to maximize the useful heat from each pond.

\subsubsection{Configuration in series}

For all types of area distribution, it was found that solar ponds connected in series achieve higher temperatures than a single SGSP (Figure 7a). When the number of solar ponds increases, the final temperature increases. However, there is a threshold where an increase in the total volume of solar ponds does not increase the final temperature. Consequently, there is an optimum number of solar ponds for which the final temperature of the SGSP field is maximum.

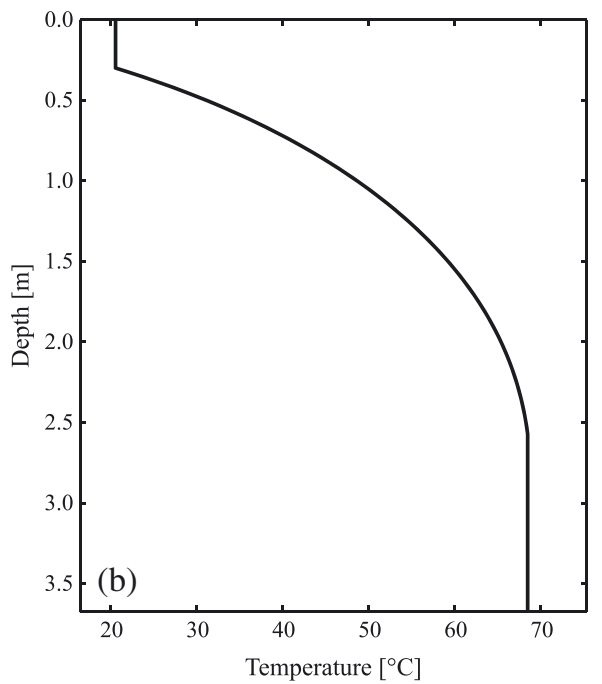

Figure 6 Optimization of the depth of the LCZ-NCZ interface for a single SGSP. (a) The temperatures of the heat exchanger streams as a function of $z_{L}$. (b) The temperature profile in the SGSP for the optimal depth. 

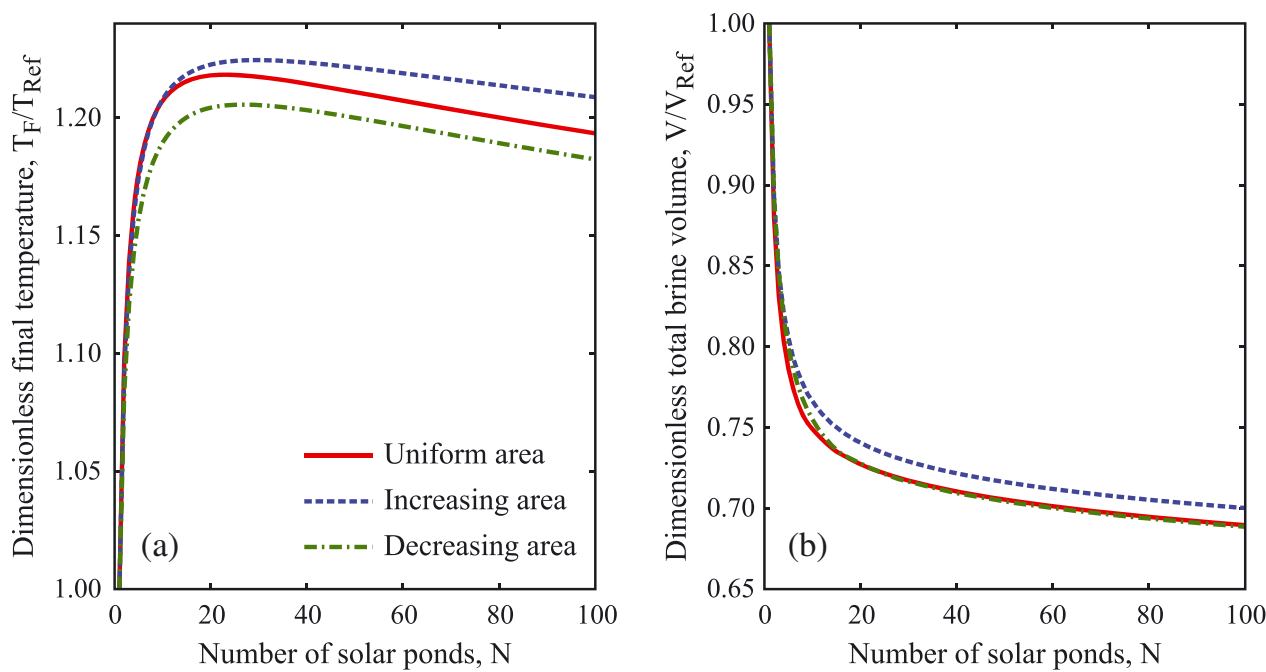

Figure 7 Performance of the configurations in series with different area distributions. (a) Dimensionless final temperature of the SGSP field. (b) Dimensionless brine volume of the SGSP field.

We found that the optimum numbers of solar ponds are 23, 30 and 27 , for ponds with uniform, increasing and decreasing area distribution, respectively. The corresponding final temperature increase of each area distribution are $22.1 \%$ $\left(11.5^{\circ} \mathrm{C}\right), 22.9 \%\left(11.8^{\circ} \mathrm{C}\right)$ and $20.4 \%\left(10.8^{\circ} \mathrm{C}\right)$, compared with the results of a single SGSP. Therefore, ponds connected in series with increasing area distribution yield more useful energy, i.e. a higher final temperature (for an optimal number of solar ponds).

When the number of solar ponds increases, the total brine volume required for the SGSP field decreases for any area distribution (Figure 7b). In general, the uniform distribution is the configuration that uses the least total brine. For optimal conditions $(N=30)$, the increasing area distribution uses $27.1 \%\left(23,106 \mathrm{~m}^{3}\right)$ less brine than a single SGSP.

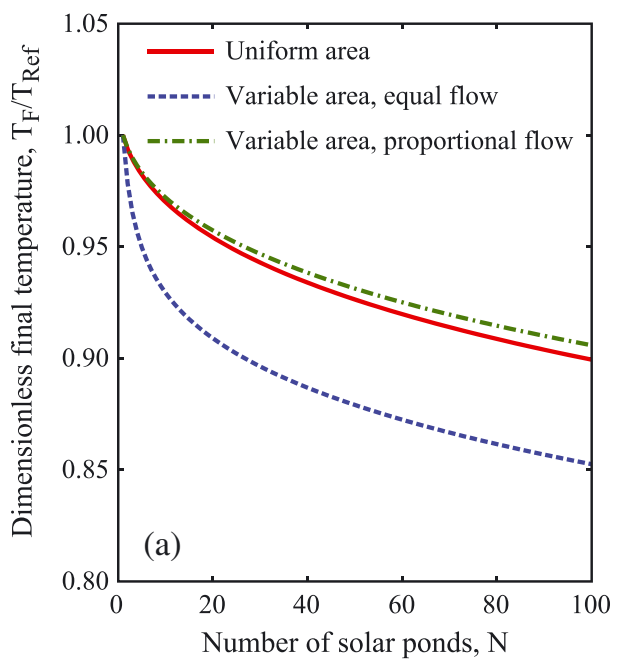

\subsubsection{Configuration in paralle}

For all the configurations in parallel, the final temperature of the SGSP field decreases compared to a single SGSP (Figure 8a). In addition, when the number of solar ponds increases, the final temperature decreases. Therefore, the optimal number of solar ponds for any area distribution is two. In terms of the final temperature reached, the best configuration is the variable area distribution with the mass flow rate distributed in proportion to the surface area of each solar pond. Noteworthy is that for a small number of solar ponds $(N<5)$, the configuration with uniform area distribution is practically the same as the configuration with variable area distribution and proportional mass flow rate.

The total brine volume of the SGSP field also decreases as the number of solar ponds increases (Figure 8b), except

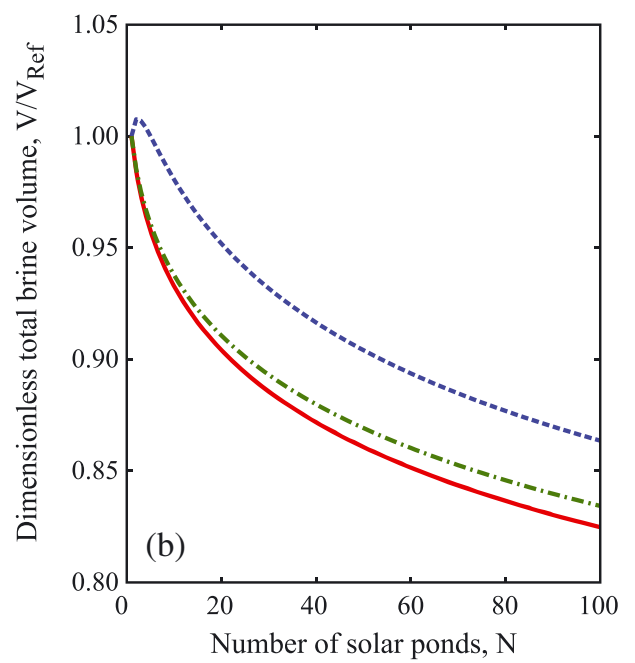

Figure 8 Performance of the configurations in parallel with different area distributions. (a) Dimensionless final temperature of the SGSP field. (b) Dimensionless brine volume of the SGSP field. 
for the case $N=2$ for variable area with equal flow. The uniform area distribution reaches the minimum total brine volume regardless the number of solar ponds.

\subsubsection{Mixed series-parallel configuration}

In the mixed configuration, the final temperatures achieved are between the final temperatures of the series and parallel configurations (Figure 9). These temperatures are always greater than for a single pond. The optimal number of solar ponds (49) is greater than the optimal number for the configuration in series, because the mixed configuration has fewer solar ponds connected in series (seven) than the configuration in series, which according to our results is more efficient than the parallel configuration. This is discussed in greater detail below. The mixed configuration reaches a final temperature that is $13.8 \%$ greater than that of a single SGSP. In terms of brine volume, the final brine volumes achieved are between the brine volumes of the series and parallel configurations. These volume data are not shown.

\subsubsection{Tree-shaped configuration}

All the tree-shaped configurations achieved intermediate final temperatures and brine volumes, relative to the series and parallel configurations. Furthermore, all the tree-shaped configurations reached final temperatures higher than in a single pond (Figure 9). The tree-shaped configuration with the highest final temperature is the mixed decreasing-increasing type, because the decreasing and the increasing configurations use more solar ponds connected in parallel for the same total amount of ponds, whereas the mixed decreasing-increasing configurations use more solar ponds connected in series. The optimal number of solar ponds for mixed decreasingincreasing configuration is 30 (eight levels), reaching a final temperature that is $17.0 \%$ greater than a single SGSP.

\section{DISCUSSION}

There are two important factors that determine the optimal depth of each solar pond: the surface area and the cold stream inlet temperature. As these factors increase, the optimal depth increases. The single solar pond has the largest surface area; consequently, it is the deepest pond of all the configurations. For the configurations that have ponds with smaller surface area and low cold stream inlet temperature, such as the ponds connected in parallel or the first ponds in the series connection, the solar ponds will be shallow and the total brine volume, required to operate under optimal conditions, will be less than a single SGSP.

Even though it has been reported that the performance of larger solar ponds is better than that of smaller ponds, as edge losses per unit area are smaller, we found that the solar ponds that are connected in series behave differently. When useful energy is extracted from the pond, the LCZ temperature also depends on the outlet temperature of the heat exchanger cold stream (or the mass flow rate of the fluid to be heated). Therefore, higher final temperatures in the SGSP field will be reached if the cold stream that enters the heat exchanger is preheated. In other words, when the ponds are connected in series, the preceding solar ponds heat the cold stream of the ponds that follow. Thus, it is easier to obtain higher temperatures and a better performance (compared to a single pond). There comes a point where adding more solar ponds becomes inefficient because the total heat losses through the sidewalls increase significantly as the perimeter per unit area increases (Figure 10). Our results show that the benefit of preheating the cold stream is more important than the benefit of having larger ponds.

Although the uniform distribution area for the series configuration appears to be the best configuration for a reduced number of solar ponds $(N<9)$, sidewall heat losses begin to be relevant when the number of solar ponds increases, because the SGSP field with uniform area distribution has a greater total perimeter per unit area than the SGSP field with increasing area distribution (Figure 10).

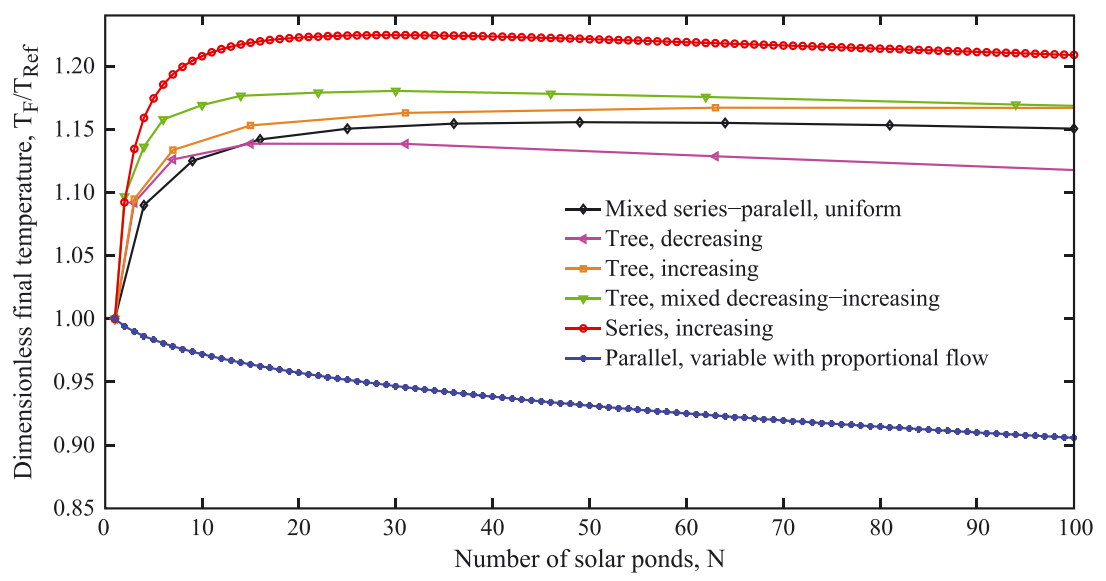

Figure 9 Dimensionless final temperature of the SGSP field for the configurations evaluated in this study. For the series configuration only the increasing area is shown, whereas for the parallel configuration only the variable area with proportional flow rate is shown. 


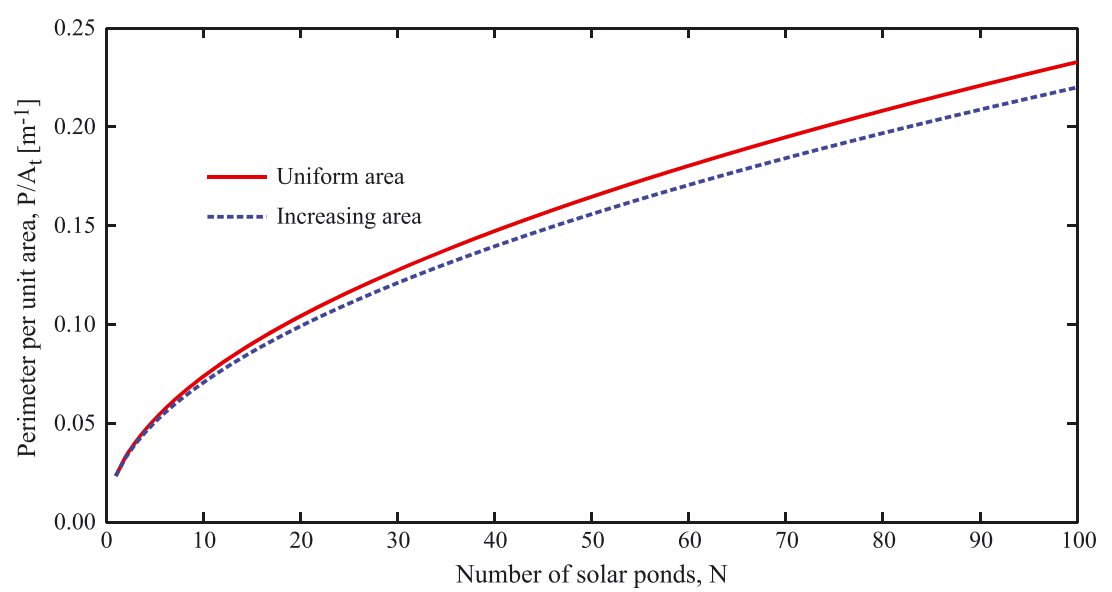

Figure 10 Perimeter per unit area for an SGSP field with N solar ponds connected in series and for ponds with uniform and increasing area distribution.

Consequently, when the number of solar pond increases, the SGSP field with increasing area distribution reaches larges temperatures than those obtained when all the ponds have the same area.

In parallel configurations, we expected that by dividing the total stream in several currents, higher temperatures in each solar pond could have been reached because less energy is required to heat a smaller fluid volume. Nonetheless, the sidewall heat losses become increasingly important as the number of solar ponds is increased. If the sidewalls were completely insulated, the parallel configuration reaches a final temperature identical to that of a single SGSP. However, heat losses are inevitable (e.g. see $[3,4,52]$ ) and increase with the number of solar ponds.

In other constructal theory studies, the tree-shaped flow architecture appeared as the best flow architecture [16,23]. However, in this study the tree-shaped configuration is not the best because its design is the result of a combination between connections in series and in parallel, and we showed that the parallel connection undermines the overall efficiency. Lorente et al. [18] highlight that the answer to the correct arrangement of solar chimney power plants ('few large and many small') is generally applicable to all types of power harvesting techniques from land areas that possess low-density resources. They concluded that the most important factor is the land area allocated to the largest plant. This conclusion can be extrapolated to the SGSP field with ponds connected in parallel, because when the ponds of this configuration have variable area distribution, the larger ponds will generate more energy per unit area than the smaller ponds (data now shown). However, the conclusion of Lorente et al. [18] cannot be extrapolated to the SGSP field with ponds connected in series, because in this configuration the solar ponds do not work independently, as they do when they are connected in parallel or in the case of the solar chimneys.

Important is to perform a sensitivity analysis to determine the impact of the total area (in which the total flow is proportional to the total area) and of the climatic conditions on the
SGSP field performance (Table II). This sensitivity analysis can be used as a planning tool for solar pond construction to achieve the highest performance of an SGSP field in a determined geographical location. This analysis was performed for the configuration in series with increasing area distribution. On one hand, when the total surface area increases, the optimal number of solar ponds also increases. When the land area is smaller than $1000 \mathrm{~m}^{2}$, the optimal number of solar ponds is less than 12, regardless the geographical location. For land areas larger than $50000 \mathrm{~m}^{2}$, the optimal number of solar ponds is always greater than 19 (see Table II for intermediate values). As the total available land area increases, the percentage difference in final temperature (or useful energy) between the series configuration and the single solar pond also increases: this is independent of geographical location. When the total land area increases the perimeter per unit area decreases (Figure 11). Therefore, more solar ponds connected in series are needed before heat losses begin to be relevant.

The optimum number of solar ponds is proportional to the insolation of the place where the SGSP field will be built. An SGSP field constructed in a northern European climate (insolation of $\sim 100 \mathrm{~W} / \mathrm{m}^{2}$ ) will require approximately half the number of ponds than those required for a tropical or subtropical climate $\left(250 \mathrm{~W} / \mathrm{m}^{2}\right)$. As solar radiation increases, the percentage difference in final temperature also increases. In tropical or subtropical climates, the final temperature increase is greater than $20 \%$. Indeed, our results indicate that in an SGSP field located in a tropical climate with a land area greater than $50000 \mathrm{~m}^{2}$ the final temperature is $25 \%$ greater than in a single SGSP (useful energy of 3.1 MW for the series configuration and 2.3 MW for the single pond). Therefore, replacing the single pond with several ponds in series is especially valuable for large land areas or high solar radiation.

In this paper, it was assumed that the heat losses in the piping system that connect the ponds are negligible. To understand the effect of this assumption on the results, the energy losses in the piping system for the SGSP field with 
Table II. Sensitivity analysis for the configuration in series for circular solar ponds with increasing area distribution and for different climates. The insolation data were obtained from Hull et al. [12]; the total flow was calculated proportional to the total area. The dimensionless useful energy corresponds to $\bar{E}=E / E_{\text {ref, }}$ where $E$ is the total useful energy extracted of each configuration and $E_{r e f}$ is the useful energy extracted of a single SGSP (that changes for each case).

\begin{tabular}{|c|c|c|c|c|c|}
\hline \multicolumn{6}{|c|}{ Tropical and subtropical climate (Latitude 0-29': insolation $242 \mathrm{~W} / \mathrm{m}^{2}$ ) } \\
\hline $\begin{array}{l}\text { Total area, } \\
\text { At }\left[\mathrm{m}^{2}\right]\end{array}$ & $\begin{array}{l}\text { Optimal number } \\
\text { of solar ponds }\end{array}$ & $\begin{array}{l}\text { Final temperature of a } \\
\text { single SGSP, } T_{r e f}\left[{ }^{\circ} \mathrm{C}\right]\end{array}$ & $\begin{array}{l}\text { Dimensionless final } \\
\text { temperature, } \bar{T}\end{array}$ & $\begin{array}{l}\text { Useful energy of a } \\
\text { single SGSP, } E_{r e f}[\mathrm{~kW}]\end{array}$ & $\begin{array}{l}\text { Dimensionless } \\
\text { useful energy, }\end{array}$ \\
\hline 1000 & 12 & 55.0 & 1.20 & 43 & 1.27 \\
\hline 10000 & 23 & 57.6 & 1.23 & 458 & 1.31 \\
\hline 50000 & 37 & 58.5 & 1.25 & 2333 & 1.33 \\
\hline \multicolumn{6}{|c|}{ Mediterranean to northern U.S. climate (latitude $30-43^{\circ}$ : insolation $193 \mathrm{~W} / \mathrm{m}^{2}$ ) } \\
\hline $\begin{array}{l}\text { Total area, } \\
\text { At }\left[\mathrm{m}^{2}\right]\end{array}$ & $\begin{array}{l}\text { Optimal number } \\
\text { of solar ponds }\end{array}$ & $\begin{array}{l}\text { Final temperature of a } \\
\text { single SGSP, } T_{\text {ref }}\left[{ }^{\circ} \mathrm{C}\right]\end{array}$ & $\begin{array}{l}\text { Dimensionless final } \\
\text { temperature, } \bar{T}\end{array}$ & $\begin{array}{c}\text { Useful energy of a } \\
\text { single SGSP, } E_{r e f}[\mathrm{~kW}]\end{array}$ & $\begin{array}{l}\text { Dimensionless } \\
\text { useful energy, } \vec{E}\end{array}$ \\
\hline 1000 & 10 & 46.0 & 1.17 & 33 & 1.25 \\
\hline 10000 & 20 & 48.2 & 1.20 & 356 & 1.29 \\
\hline 50000 & 33 & 48.9 & 1.22 & 1815 & 1.32 \\
\hline \multicolumn{6}{|c|}{ Intermediate climate (latitude $44-49^{\circ}:$ insolation $145 \mathrm{~W} / \mathrm{m}^{2}$ ) } \\
\hline $\begin{array}{l}\text { Total area, } \\
\text { At }\left[\mathrm{m}^{2}\right]\end{array}$ & $\begin{array}{l}\text { Optimal number } \\
\text { of solar ponds }\end{array}$ & $\begin{array}{l}\text { Final temperature of a } \\
\text { single SGSP, } T_{\text {ref }}\left[{ }^{\circ} \mathrm{C}\right]\end{array}$ & $\begin{array}{l}\text { Dimensionless final } \\
\text { temperature, } \bar{T}\end{array}$ & $\begin{array}{l}\text { Useful energy of a } \\
\text { single SGSP, } E_{r e f}[\mathrm{~kW}]\end{array}$ & $\begin{array}{l}\text { Dimensionless } \\
\text { useful energy, } \vec{E}\end{array}$ \\
\hline 1000 & 8 & 37.1 & 1.13 & 24 & 1.22 \\
\hline 10000 & 16 & 39.0 & 1.16 & 256 & 1.26 \\
\hline 50000 & 27 & 39.6 & 1.18 & 1310 & 1.29 \\
\hline \multicolumn{6}{|c|}{ Northern European climate (latitude 50-53: insolation $97 \mathrm{~W} / \mathrm{m}^{2}$ ) } \\
\hline $\begin{array}{l}\text { Total area, } \\
\text { At }\left[\mathrm{m}^{2}\right]\end{array}$ & $\begin{array}{l}\text { Optimal number } \\
\text { of solar ponds }\end{array}$ & $\begin{array}{l}\text { Final temperature of a } \\
\text { single SGSP, } T_{\text {ref }}\left[{ }^{\circ} \mathrm{C}\right]\end{array}$ & $\begin{array}{l}\text { Dimensionless final } \\
\text { temperature, } \bar{T}\end{array}$ & $\begin{array}{l}\text { Useful energy of a } \\
\text { single SGSP, } E_{\text {ref }}[\mathrm{kW}]\end{array}$ & $\begin{array}{l}\text { Dimensionless } \\
\text { useful energy, } \dot{E}\end{array}$ \\
\hline 1000 & 5 & 28.3 & 1.07 & 14 & 1.16 \\
\hline 10000 & 11 & 29.8 & 1.10 & 156 & 1.22 \\
\hline 50000 & 19 & 30.2 & 1.12 & 806 & 1.24 \\
\hline
\end{tabular}

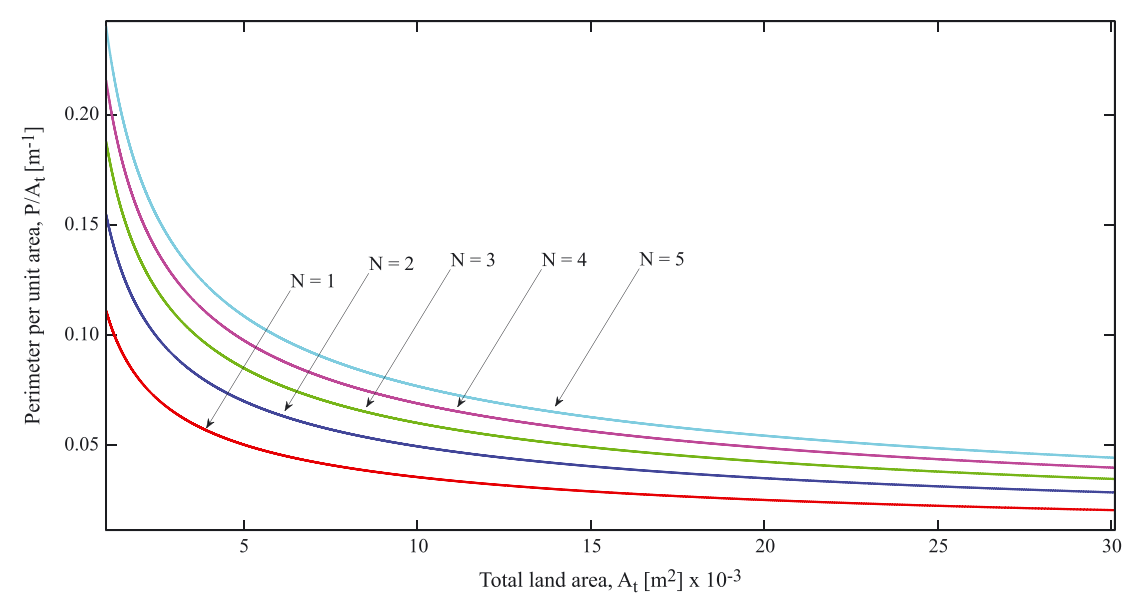

Figure 11 Perimeter per unit area as a function of the total land area $A_{t}$ for an SGSP field ( $N=1$ to 5 ) with ponds connected in series and increasing area distribution.

ponds connected in series were estimated. The heat losses through the pipes between each heat exchanger were determined as [53]:

$$
T_{\text {out }}=T_{g}-\frac{T_{g}-T_{\text {in }}}{\exp \left(\frac{h_{p} P_{p} L_{p}}{\rho A_{p} v C_{p}}\right)}
$$

where $T_{\text {out }}$ is the temperature of a fluid with density $\rho$ and velocity $v$, at the end of a pipe of length $L_{p}$, cross-sectional area $A_{p}$, perimeter $P$ and heat transfer coefficient through the pipe wall $h_{p} ; T_{g}$ is the ground temperature and $T_{i n}$ is the temperature that the fluid has at the inlet of the pipe. The length of each pipe was determined for each configuration assuming that the heat exchanger is located below 


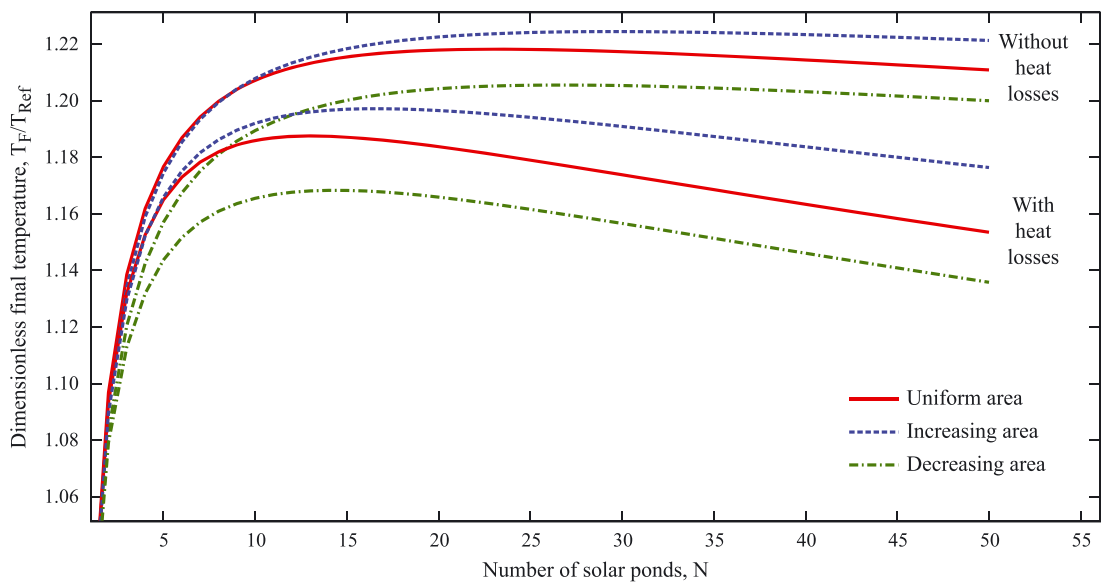

Figure 12 Comparison of the SGSP field final temperatures with ponds connected in series with and without heat losses in the piping system. The results are shown for uniform, increasing and decreasing area distribution.

and at the center of each SGSP. Assuming a heat transfer coefficient in the pipes of $13.1 \mathrm{~W} / \mathrm{m}^{2} \mathrm{~K}$ (heat losses toward the ground), a friction factor of 0.015 and $0.10-\mathrm{m}$ diameter pipe, a single SGSP with a piping system subject to heat losses has a final temperature that is $1.6^{\circ} \mathrm{C}$ lower than that of the system without heat losses (for the meteorological conditions of the province of Copiapó). For the SGSP field with configuration in series, it was found that the optimum number of solar ponds decreases for each configuration, and that the final temperature of the SGSP field also decreases (Figure 12). Note that when including heat losses in the piping system, the previous discussions and conclusions are still valid.

An advantage of having multiple SGSPs is that when a solar pond requires maintenance and must be stopped, the other ones can keep running and producing energy. In this situation, the pipe network needs to be designed in a way that allows the correct operation of the SGSP field even when one pond is not operating. For parallel connections this is not a problem, because the parallel connection itself creates many pathways for the circulation of the fluid to be heated. However, the series connection requires a bypass around each heat exchanger to allow the correct operation of the SGSP field.

Finally, it is important to emphasize that the analysis performed in this work only focused on the heat transfer aspects of the SGSP field. A design of an SGSP field must consider other aspects, e.g. investment and operational costs, and pressure drop in the pipe network, which can also be assessed using constructal design. Investment and operational costs can be analyzed by minimizing the resistance of the cash flow, and pressure drop in the pipe network can be examined by minimizing the fluid flow resistance. In this last case, it is interesting to note that when the total volume of the pipe network is fixed, the ponds connected in series remain the best configuration (data not shown), but this result may change depending on the constraints imposed to the problem.

\section{CONCLUSIONS}

We demonstrated that contructal theory enables the design of SGSP fields. In this study, several configurations of an SGSP field were assessed. The two basic configurations evaluated in this study (series vs. parallel) delivered opposite results: the series configuration performs better than a single SGSP as the preceding solar ponds in series connection preheat the mass flow rate of the following ponds. In contrast, the parallel configuration fails to deliver temperatures higher than in a single SGSP because of the increased sidewalls heat losses. Intermediate final temperatures between the series and the parallel configurations were obtained in the mixed series-parallel and in the tree-shaped configurations.

It was found that the best configuration is obtained when the ponds are connected in series with an increasing area distribution. For the study site of this investigation, the optimum number of solar ponds is 30 . This SGSP field reaches a final temperature that is $22.9 \%$ higher than that of a single SGSP, and uses $27.1 \%$ less brine than a single SGSP. These values vary depending on the land area and on the specific geographical location. Experimental results of these configurations would be useful in future works to corroborate the theoretical results obtained in this study.

\section{NOMENCLATURE}

$\begin{array}{lrl}h_{p} & =\text { heat transfer coefficient of the pipe walls } \\ & {\left[\mathrm{W} / \mathrm{m}^{2} / \mathrm{K}\right]} \\ = & \text { mass flow rate of fluid to be heated }[\mathrm{kg} / \mathrm{s}] \\ = & \text { heat loss through the bottom of the pond } \\ & {[\mathrm{W}]} \\ q_{b} & \text { heat conduction from NCZ to } \mathrm{LCZ}[\mathrm{W}] \\ = & \text { shortwave radiation that penetrates the } \\ & \\ q_{k L} & \text { water surface }[\mathrm{W}] \\ q_{o} & \text { shortwave radiation stored in the UCZ }[\mathrm{W}] \\ q_{r U} & =\end{array}$




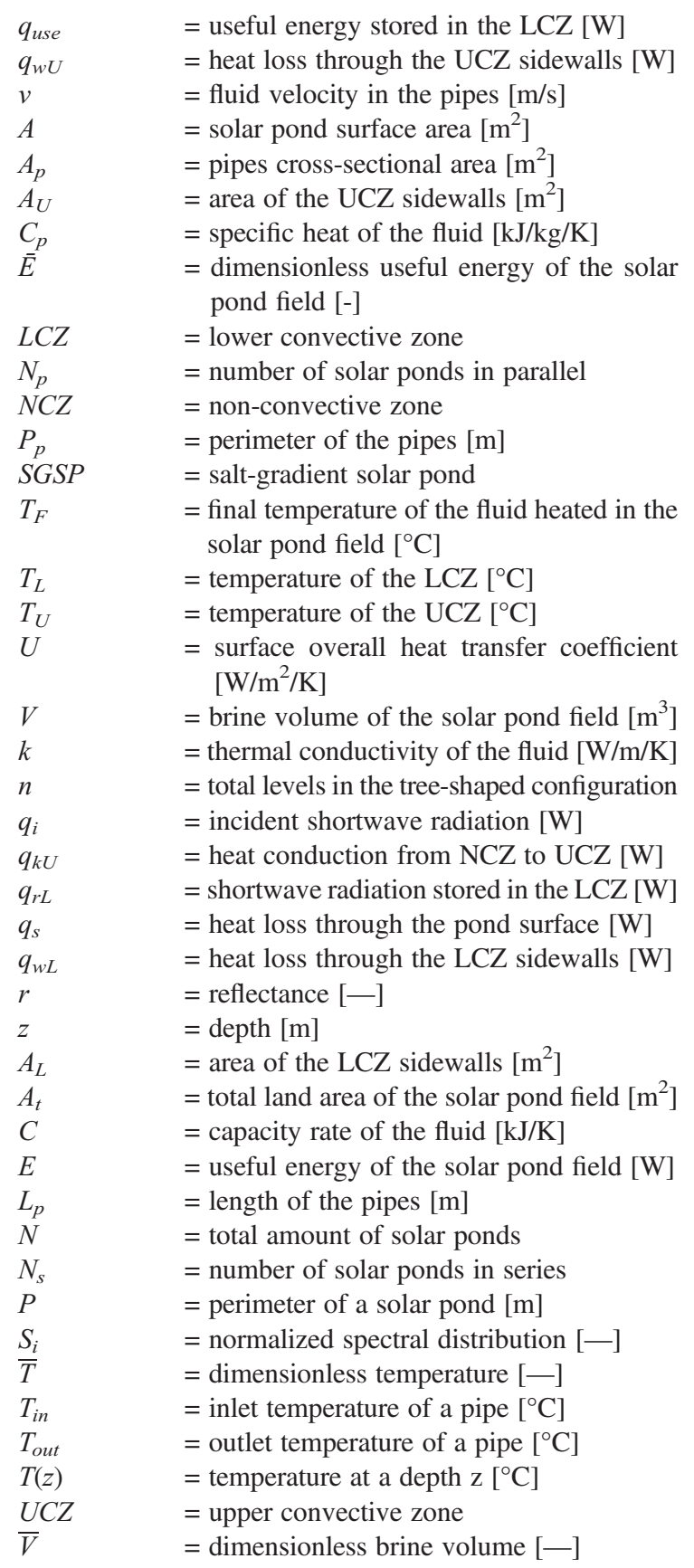

Greek symbols

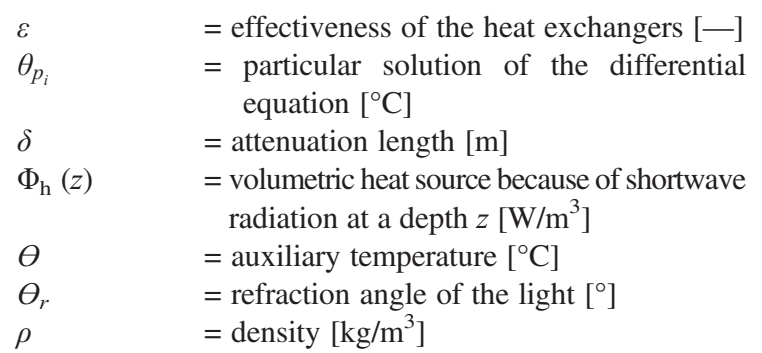

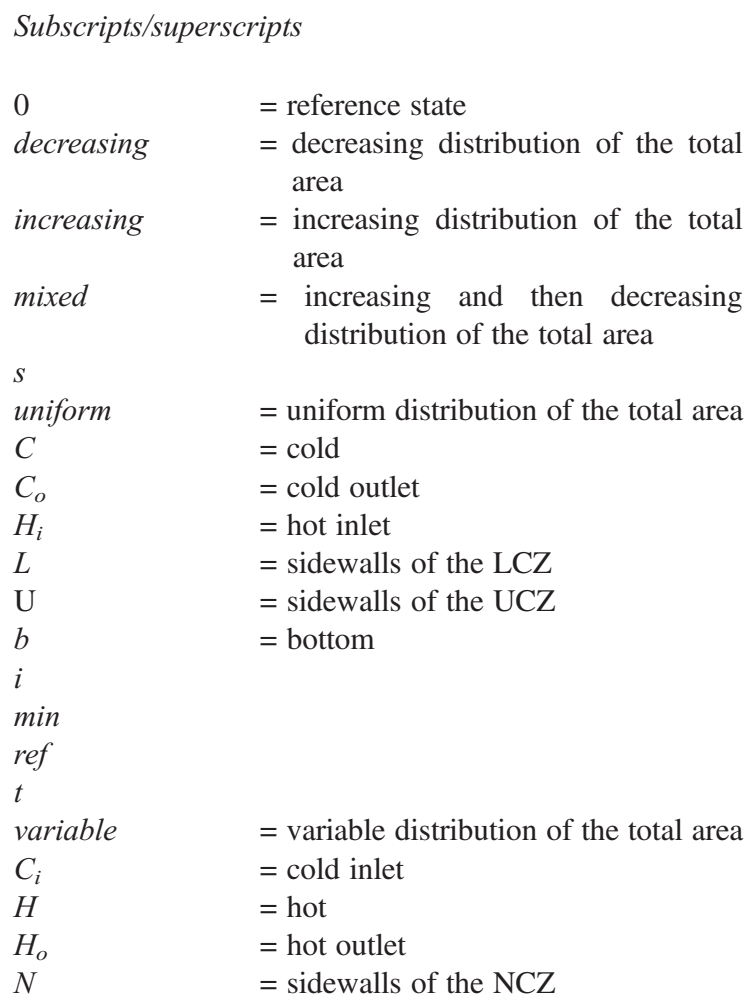

0

decreasing

increasing

mixed

$S$

uniform = uniform distribution of the total area

$C \quad$ = cold

$C_{o} \quad=$ cold outlet

$H_{i} \quad$ = hot inlet

$L=$ sidewalls of the LCZ

$\mathrm{U} \quad$ = sidewalls of the UCZ

b $\quad$ bottom

$\min$

ref

$t$

variable $\quad=$ variable distribution of the total area

$C_{i} \quad=$ cold inlet

H $\quad$ hot

$H_{o} \quad$ = hot outlet

$N \quad$ = sidewalls of the NCZ

\section{APPENDIX A. Mathematical Model}

The energy balance in the UCZ can be represented as (Figure A.1):

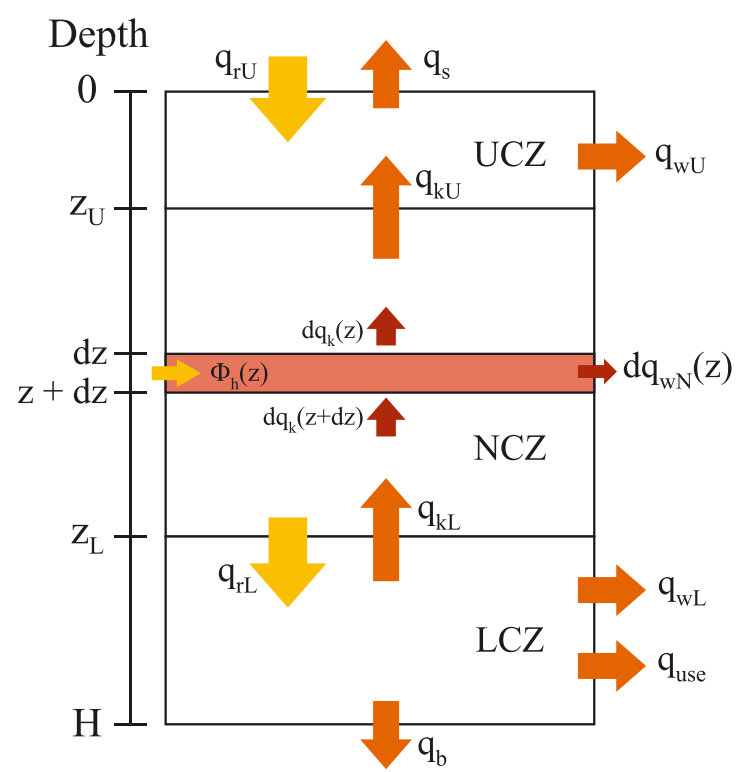

Figure A.1. Energy balance in the three zones of an SGSP. The differential element of thickness $d z$ is used to determine the thermal profile in the NCZ. 


$$
q_{r U}=q_{s}+q_{w U}+q_{k U}
$$

where $q_{r U}$ is the difference between the shortwave radiation that reaches the surface of the pond $(z=0)$ and the shortwave radiation that crosses the UCZ-NCZ interface $\left(z=z_{U}\right), q_{s}$ is the heat loss through the water surface, $q_{w U}$ is the heat loss through the sidewalls of the UCZ and $q_{k U}$ is the conductive heat flux coming from the NCZ, which is determined using Fourier's Law:

$$
q_{k U}=-\left.k A \frac{\partial T(z)}{\partial z}\right|_{z_{U}}
$$

where $A$ is the surface area of the solar pond, $k$ is the thermal conductivity of the fluid, and $T(z)$ is the temperature at a depth $z$. A similar analysis for the LCZ yields (Figure A.1):

$$
q_{r L}+q_{k L}=q_{b}+q_{w L}+q_{u s e}
$$

where $q_{r L}$ is the shortwave radiation that crosses the NCZLCZ interface $\left(z=z_{L}\right), q_{b}$ is the heat loss through the bottom of the pond, $q_{w L}$ is the heat loss through the sidewalls of the $\mathrm{LCZ}, q_{\text {use }}$ is the useful energy extracted from the LCZ and $q_{k L}$ is the conductive heat flux transmitted to the NCZ, given by:

$$
q_{k L}=-\left.k A \frac{\partial T(z)}{\partial z}\right|_{z_{L}} .
$$

The other heat fluxes are estimated as follows:

$$
\begin{gathered}
q_{r U}=A^{*}\left(q_{r}^{\prime \prime}(0)-q_{r}^{\prime \prime}\left(z_{U}\right)\right) \\
q_{s}=U_{s} A\left(T_{U}-T_{\text {air }}\right) \\
q_{w U}=U_{U} A_{U}\left(T_{U}-T_{g}\right) \\
q_{r L}=A q_{r}^{\prime \prime}\left(z_{L}\right) \\
q_{b}=U_{b} A\left(T_{L}-T_{g}\right) \\
q_{w L}=U_{L} A_{L}\left(T_{L}-T_{g}\right) \\
q_{u s e}=C_{H}\left(T_{L}-T_{H o}\right)
\end{gathered}
$$

where $q_{r}^{\prime \prime}(z)$ is the shortwave radiation flux at a depth $z ; U_{s}$, $U_{U}, U_{L}$ and $U_{b}$ are the overall heat transfer coefficient across the surface, the UCZ, the LCZ and the bottom of the pond, respectively; $A_{U}$ and $A_{L}$ are the lateral areas of the UCZ and LCZ (i.e. wetted perimeter times the thickness of each zone), respectively; $T_{U}$ and $T_{L}$ are the temperatures of the UCZ and LCZ, respectively; $T_{\text {air }}$ is the air temperature, $T_{g}$ is the ground temperature, $T_{H o}$ is the temperature of the brine that enters the $\mathrm{LCZ}$ after warmed in the hot side of the heat exchanger and $C_{H}$ is the product of the specific heat of the brine and the brine mass flow rate that recirculates between the SGSP and the heat exchanger. The attenuation of the shortwave radiation is represented using the Rabl and Nielsen formula [6]:

$$
q_{r}(z)=q_{o} \sum_{i=1}^{4} S_{i} e^{\frac{-z}{\cos \left(\theta_{r}\right) \delta_{i}}}
$$

where $q_{r}^{\prime \prime}(z)$ is the shortwave radiation flux at a depth $z ; S_{i}$ and $\delta_{i}$ are parameters to determine the attenuation of light within the water column; $\theta_{r}$ is the refraction angle of the light and $q_{o}$ represents the solar radiation that penetrates the water surface,

$$
q_{o}=(1-r) q_{i}
$$

where $q_{i}$ is the incident radiation, and $r(=0.06)$ is the reflectance of the solar radiation at the water surface [32].

Because the temperature in the $\mathrm{NCZ}$ is not uniform, the analysis in this zone is different than that of the UCZ and LCZ. Because of the density gradient, the fluid in the $\mathrm{NCZ}$ is static, and thus the main heat transfer mechanisms in this zone are conduction and solar radiation absorption. To estimate the thermal profile within the NCZ, a differential analysis yields (Figure A.1):

$$
\begin{gathered}
\Phi_{h} A d z=d q_{w N}+d q_{k} \\
\Phi_{h} A d z=U_{N} P d z\left(T(z)-T_{g}\right)+d\left(-k A \frac{\partial T(z)}{\partial z}\right) \\
\Phi_{h} A=U_{N} P\left(T(z)-T_{g}\right)+\frac{d}{d z}\left(-k A \frac{\partial T(z)}{\partial z}\right)
\end{gathered}
$$

where $q_{w N}$ is the heat loss through the sidewalls of the $\mathrm{NCZ}, q_{k}$ is the conductive heat flux through the NCZ, $U_{N}$ is the overall heat transfer coefficient of the NCZ sidewalls, $P$ is the perimeter of the pond and $\Phi_{h}$ is the shortwave radiation, modeled as a volumetric heat source [6]:

$$
\Phi_{h}(z)=-\frac{\partial q_{r}^{\prime \prime}}{\partial z}=\frac{q_{o}}{\cos \left(\theta_{r}\right)} \sum_{i=1}^{4} \frac{S_{i}}{\delta_{i}} e^{\frac{-z}{\cos \left(\theta_{r}\right) \delta_{i}}} .
$$

Defining the auxiliary variables $\theta(z)=T(z)-T_{g}$, and $\xi=\sqrt{\frac{k^{*} A}{U_{n}{ }^{*} P}}$, equation (A.16) can be written as

$$
\frac{\partial^{2} \theta(z)}{\partial z^{2}}-\frac{\theta(z)}{\xi^{2}}=-\frac{\Phi_{h}(z)}{k}
$$

The solution of equation (A.18) is

$$
\theta(z)=C_{1} e^{-z / \xi}+C_{2} e^{z / \xi}+\sum_{i=1}^{4} \theta_{p_{i}}(z)
$$

where each particular solution has the form

$$
\theta_{p_{i}}(z)=B_{i} e^{\frac{-z}{\cos \left(\theta_{r}\right) \delta_{i}}}
$$

and $B_{i}$ is a constant that can be found replacing each particular solution into equation (A.18): 


$$
B_{i}=\frac{q_{o} S_{i}}{k \cos \left(\theta_{r}\right) \delta_{i}}\left(\frac{1}{\xi^{2}}-\frac{1}{\cos ^{2}\left(\theta_{r}\right) \delta_{i}^{2}}\right)^{-1}
$$

Thus, the thermal profile in the NCZ is given by:

$$
T(z)=T_{g}+C_{1} e^{-z / \xi}+C_{2} e^{z / \xi}+\sum_{i=1}^{4} B_{i} e^{\frac{-z}{\cos \left(\theta_{r}\right) \delta_{i}}} .
$$

The constants $C_{1}$ and $C_{2}$ are obtained from the boundary conditions $T\left(z_{U}\right)=T_{U}$ and $T\left(z_{L}\right)=T_{L}$,

$C_{1}=\frac{T_{L} e^{z_{U} / \xi}-T_{g} e^{z_{U} / \xi}-T_{U} e^{z_{L} / \xi}+T_{g} e^{z_{L} / \xi}+F_{z U} e^{z_{L} / \xi}-F_{z_{L}} e^{z_{U} / \xi}}{e^{-z_{L} / \xi} e^{z_{U} / \xi}-e^{-z_{U} / \xi} e^{z_{L} / \xi}}$

$C_{2}=\frac{-T_{L} e^{-z_{U} / \xi}+T_{g} e^{-z_{U} / \xi}+T_{U} e^{-z_{L} / \xi}-T_{g} e^{-z_{L} / \xi}-F_{z_{U}} e^{-z_{L} / \xi}+F_{z_{L}} e^{-z_{U} / \xi}}{e^{-z_{L} / \xi} e^{z_{U} / \xi}-e^{-z_{U} / \xi} e^{z_{L} / \xi}}$

where $\quad F_{z_{U}}=\sum_{i=1}^{4} B_{i} e^{\frac{-z_{U}}{\cos \left(\theta_{r}\right) \delta_{i}}}$ and $F_{z_{L}}=\sum_{i=1}^{4} B_{i} e^{\frac{-z_{L}}{\cos \left(\theta_{r}\right) \delta_{i}}}$. Substituting equation (A.22) into equations (A.2) and (A.4) yields:

$q_{k U}=-k A\left(-\frac{C_{1}}{\xi} e^{-\frac{z_{U}}{\xi}}+\frac{C_{2}}{\xi} e^{\frac{z_{U}}{\xi}}-\frac{1}{\cos \left(\theta_{r}\right)} \sum_{i=1}^{4} \frac{B_{i}}{\delta_{i}} e^{\frac{-z_{U}}{\cos \left(\theta_{r}\right) \delta_{i}}}\right)$

$q_{k L}=-k A\left(-\frac{C_{1}}{\xi} e^{-\frac{z_{L}}{\xi}}+\frac{C_{2}}{\xi} e^{\frac{z_{L}}{\xi}}-\frac{1}{\cos \left(\theta_{r}\right)} \sum_{i=1}^{4} \frac{B_{i}}{\delta_{i}} e^{\frac{-z_{L}}{\cos \left(\theta_{r}\right) \delta_{i}}}\right)$.

The previous equations can be then used to determine the temperatures in the UCZ and $\mathrm{LCZ}$, and to find the thermal distribution in the NCZ via equation (A.22).

\section{APPENDIX B. Temperatures in the Heat Exchanger}

To analyze the temperatures in the heat exchanger, the concept of effectiveness, $\varepsilon$, was used [51]:

$$
\varepsilon=\frac{C_{H}\left(T_{H i}-T_{H o}\right)}{C_{\min }\left(T_{H i}-T_{C i}\right)}=\frac{C_{C}\left(T_{C o}-T_{C i}\right)}{C_{\min }\left(T_{H i}-T_{C i}\right)}
$$

where $T_{H i}$ and $T_{H o}$ are the inlet and outlet hot stream temperatures, respectively; $T_{C i}$ and $T_{C o}$ are the inlet and outlet cold stream temperatures, respectively; $C_{H}$ and $C_{C}$ are the capacity rates of the hot and cold streams, respectively; and $C_{\min }$ is the minimum between $C_{H}$ and $C_{C}$. The outlet hot stream and cold stream temperatures can be found by rearranging equation (B.1), as the same as the outlet temperature of the cold side:

$$
T_{H o}=T_{H i}-\varepsilon \frac{(C p \dot{m})_{\min }}{(C p \dot{m})_{H}}\left(T_{H i}-T_{C i}\right)
$$

$$
T_{C o}=T_{C i}+\varepsilon \frac{C_{m i n}}{C_{C}}\left(T_{H i}-T_{C i}\right) .
$$

Then, the useful heating rate can be expressed as $q_{\text {use }}=\varepsilon C_{\text {min }}\left(T_{H i}-T_{C i}\right)$.

\section{ACKNOWLEDGEMENTS}

The authors thank the Comisión Nacional de Investigación Científica y Tecnológica (CONICYT), Chile, for funding project Fondecyt de Iniciación $\mathrm{N}^{\circ} 11121208$. This investigation was supported by the Centro de Desarrollo Urbano Sustentable (CEDEUS-CONICYT/FONDAP/15110020) and by the Center for Solar Energy Technologies (CSETCORFO CEI2-21803).

\section{REFERENCES}

1. Ranjan KR, Kaushik SC. Thermodynamic and economic feasibility of solar ponds for various thermal applications: a comprehensive review. Renewable and Sustainable Energy Reviews 2014; 32:123-139. doi:10.1016/j.rser.2014.01.020.

2. Ruskowitz JA, Suárez F, Tyler SW, Childress AE. Evaporation suppression and solar energy collection in a salt-gradient solar pond. Solar Energy 2014; 99:36-46. doi:10.1016/j.solener.2013.10.035.

3. Suárez F, Ruskowitz JA, Childress AE, Tyler SW. Understanding the expected performance of large-scale solar ponds from laboratory-scale observations and numerical modeling. Applied Energy 2014; 117:1-10. doi:10.1016/j.apenergy.2013.12.005.

4. Bozkurt I, Mantar S, Karakilcik M. A new performance model to determine energy storage efficiencies of a solar pond. Heat and Mass Transfer 2015; 51:39-48. doi:10.1007/s00231-014-1389-y.

5. Suárez F, Childress AE, Tyler SW. Temperature evolution of an experimental salt-gradient solar pond. Journal of Water and Climate Change 2010; 1(4):246-250. doi:10.2166/wcc.2010.101.

6. Rabl A, Nielsen CE. Solar ponds for space heating. Solar Energy 1975; 17(1):1-12. doi:10.1016/0038-092X (75)90011-0.

7. Styris DL, Harling OK, Zaworski RJ, Leshuk J. The nonconvecting solar pond applied to building and process heating. Solar Energy 1976; 18(3):245-251. doi:10.1016/0038-092X(76)90023-2.

8. Suárez F, Tyler SW, Childress AE. A theoretical study of a direct contact membrane distillation system coupled to a salt-gradient solar pond for terminal lakes reclamation. Water Research 2010; 44(15):4601-4615. doi:10.1016/j.watres.2010.05.050. 
9. Garrido F, Soto R, Vergara J, Walczak M, Kanehl P, Nel R, García J. Solar pond technology for largescale heat processing in a Chilean mine. Journal of Renewable and Sustainable Energy 2012; 4(5):053115. doi:10.1063/1.4757627.

10. Garrido F, Vergara J. Design of solar pond for water preheating used in the copper cathodes washing at a mining operation at Sierra Gorda, Chile. Journal of Renewable and Sustainable Energy 2013; 5(4):043103. doi:10.1063/1.4812652.

11. Kumar A, Kishore VVN. Construction and operational experience of a $6000 \mathrm{~m}^{2}$ solar pond at Kutch, India. Solar Energy 1999; 65(4):237-249. doi:10.1016/ S0038-092X(98)00134-0.

12. Murthy GR, Pandey KP. Scope of fertiliser solar ponds in Indian agriculture. Energy 2002; 27(2):117-126. doi:10.1016/S0360-5442(01)00059-7.

13. Singh R, Tundee S, Akbarzadeh A. Electric power generation from solar pond using combined thermosyphon and thermoelectric modules. Solar Energy 2011; 85(2):371-378. doi:10.1016/j.solener.2010.11.012.

14. Hull JR, Nielsen J, Golding P. Salinity Gradient Solar Ponds. CRC Press: Boca Ratón, Florida, 1989.

15. Tabor HZ, Doron B. The Beith Ha'Arava 5 MW(e) solar pond power plant (SPPP)— progress report. Solar Energy 1990; 45(4):247-253. doi:10.1016/0038-092X (90)90093-R.

16. Bejan A, Lorente S. Design with Constructal Theory. Wiley: Hoboken, 2008.

17. Wechsatol W, Lorente S, Bejan A. Tree-shaped insulated designs for the uniform distribution of hot water over an area. International Journal of Heat and Mass Transfer 2001; 44(16):3111-3123. doi:10.1016/S00179310(00)00338-0.

18. Lorente S, Koonsrisuk A, Bejan A. Constructal distribution of solar chimney power plants: few large and many small. International Journal of Green Energy 2010; 7(6):577-592. doi:10.1080/15435075.2010.529402.

19. Lorente S, Bejan A, Niu JL. Constructal design of latent heat thermal energy storage with vertical spin heaters. International Journal of Heat and Mass Transfer 2015; 81:283-288. doi:10.1016/j.ijheatmasstransfer. 2014.09.077.

20. Lorenzini G, Biserni C, García FL, Rocha LAO. Geometric optimization of a convective T-shaped cavity on the basis of constructal theory. International Journal of Heat and Mass Transfer 2012; 55:6951-6958. doi:10.1016/j.ijheatmasstransfer.2012.07.009.

21. Lorenzini G, Biserni C, Estrada ED, Isoldi LA, dos Santos ED, Rocha LAO. Constructal design of convective Y-shaped cavities by means of genetic algorithm. ASME Journal of Heat Transfer 2014; 136:071702. doi:10.1115/1.4027195
22. Lorente S, Lee J, Bejan A. The "flow" stresses concept: the analogy between mechanical strength and heat convection. International Journal of Heat and Mass Transfer 2010; 53:2963-2968. doi:10.1016/j. ijheatmasstransfer.2010.03.038.

23. Kim S, Lorente S, Bejan A. Vascularized materials: tree-shaped flow architectures matched canopy to canopy. Journal of Applied Physics 2006; 100(6):063525. doi:10.1063/1.2349479.

24. Lui CH, Fong NK, Lorente S, Bejan A, Chow WK. Constructal design of evacuation from a threedimensional living space. Physica A 2015; 422:47-27. doi:10.1016/j.physa.2014.12.005.

25. Feng H, Chen L, Xie Z, Sun F. Constructal design for $\mathrm{X}$-shaped hot water network over a rectangle. Applied Thermal Engineering 2015; 87:760-767. doi:10.1016/ j.applthermaleng.2015.05.070.

26. Miguel AF. Constructal design of solar energybased systems for buildings. Energy and Buildings 2008; 40(6):1020-1030. doi:10.1016/j.enbuild.2007.08. 005 .

27. Lorente S, Bejan A, Al-Hinai K, Sahin AZ, Yilbas BS. Constructal design of distributed energy systems: solar power and water desalination. International Journal of Heat and Mass Transfer 2012; 55(9):2213-2218. doi:10.1016/j.ijheatmasstransfer.2012.01.020.

28. Kurt H, Halici F, Binark AK. Solar pond conceptionexperimental and theoretical studies. Energy Conversion and Management 2000; 41(9):939-951. doi:10.1016/ S0196-8904(99)00147-8.

29. Dah MMO, Ouni M, Guizani A, Belghith A. The influence of the heat extraction mode on the performance and stability of a mini solar pond. Applied Energy 2010; 87:3005-3010. doi:10.1016/j.apenergy.2010.04.004.

30. Suárez F, Tyler SW, Childress AE. A fully coupled, transient double-diffusive convective model for saltgradient solar ponds. International Journal of Heat and Mass Transfer 2010; 53(9):1718-1730. doi:10.1016/j. ijheatmasstransfer.2010.01.017.

31. Wang H, Xie M, Sun WC. Nonlinear dynamic behavior of non-convective zone in salt gradient solar pond. Solar Energy 2011; 85(9):1745-1757. doi:10.1016/j. solener.2011.04.034.

32. Boudhiaf R, Moussa AB, Baccar M. A two-dimensional numerical study of hydrodynamic, heat and mass transfer and stability in a salt gradient solar pond. Energies 2012; 5(10):3986-4007. doi:10.3390/en5103986.

33. Weinberger H. The physics of the solar pond. Solar Energy 1964; 8(2):45-56. doi:10.1016/0038-092X (64)90046-5.

34. Kooi CF. The steady state salt gradient solar pond. Solar Energy 1979; 23(1):37-45. doi:10.1016/0038092X(79)90041-0. 
35. Wang YF, Akbarzadeh A. A parametric study on solar ponds. Solar Energy 1983; 30(6):555-562. doi:10.1016/ 0038-092X(83)90067-1.

36. Ali HM. Mathematical modelling of a salt gradient solar pond performance. International Journal of Energy Research 1986; 10(4):377-384. doi:10.1002/ er.4440100408.

37. Kirk JTO. Light and Photosynthesis in Aquatic Ecosystems. Cambridge University Press: New York, NY, USA, 1983.

38. Williamson RE. Introduction to Differential Equations: $O C D E, P D E$, and Series. Prentice-Hall: Englewood Cliffs, N.J., 1986.

39. Dehghan AA, Movahedi A, Mazidi M. Experimental investigation of energy and exergy performance of square and circular solar ponds. Solar Energy 2013; 97:273-284. doi:10.1016/j.solener.2013.08.013.

40. Lu H, Swift HP, Hein HD, Walton JC. Advancements in salinity gradient solar pond technology based on sixteen years of operational experience. Journal of Solar Energy Engineering 2004; 126(2):759-767. doi:10.1115/1.1667977.

41. Leblanc J, Akbarzadeh A, Andrews J, Lu H, Golding P. Heat extraction methods from salinity-gradient solar ponds and introduction of a novel system of heat extraction for improved efficiency. Solar Energy 2011; 85(12):3103-3142. doi:10.1016/j.solener.2010.06. 005.

42. Pramanick AK, Das PK. Constructal design of a thermoelectric device. International Journal of Heat and Mass Transfer 2006; 49(7):1420-1429. doi:10.1016/ j.ijheatmasstransfer.2005.09.028.

43. Daneshi M, Zare M, Salimpour MR. Micro-and nanoscale conductive tree-structures for cooling a diskshaped electronic piece. Journal of Heat Transfer 2013; 135(3):031401. doi:10.1115/1.4007903.

44. Feng H, Chen L, Xie Z, Sun F. Constructal optimization for tree-shaped fluid networks in a disc-shaped area subjected to the surface area constraint. Arabian
Journal for Science and Engineering 2014; 39 (2):1381-1391. doi:10.1007/s13369-013-0743-6.

45. Oyarzún J, Oyarzún R. Sustainable development threats, inter-sector conflicts and environmental policy requirements in the arid, mining rich, Northern Chile territory. Sustainable Development 2011; 19:263-274. doi:10.1002/sd.441.

46. Suárez F, Muñoz JF, Fernández B, Dorsaz J, Hunter CK, Karavatis CA, Gironás J. Integrated water resource management and energy requirements for water supply in the Copiapó river basin, Chile. Water 2014; 6:2590-2613. doi:10.3390/w6092590.

47. Suárez F, Ruskowitz JA, Tyler SW, Childress AE. Renewable water: direct contact membrane distillation coupled with solar ponds. Applied Energy 2015; 158:532-539. doi:10.1016/j.apenergy.2015.08.110.

48. SISS. Informe de Gestión del Sector Sanitario 2013. Superintendencia de Servicios Sanitarios 2014. Available at: http://www.siss.gob.cl/577/w3-propertyvalue3443.html (last accessed: August 2015)

49. Silva C. Estudio experimental y numérico del comportamiento de una piscina solar al reducir la evaporación en su superficie con discos flotantes (An experimental and numerical study of evaporation reduction in a salt-gradient solar pond using floating discs). Ms. Thesis, Pontificia Universidad Católica de Chile: Santiago, Chile, 2015.

50. Beniwal RS, Singh RV, Chaudhary DR. Heat losses from a salt-gradient solar pond. Applied Energy 1985; 19(4):273-285. doi:10.1016/0306-2619(85)90002-9.

51. Mills AF. Heat Transfer (second ed). Prentice Hall Inc.,: New Jersey, 1999.

52. Karakilcik M, Kıymaç K, Dincer I. Experimental and theoretical temperature distributions in a solar pond. International Journal of Heat and Mass Transfer 2006; 49(5-6):825-835. doi:10.1016/j.ijheatmasstransfer. 2005.09.026.

53. Bejan A. Convection Heat Transfer (4th ed). Wiley: Hoboken, 2013. 